\title{
Geotermometria das águas hipertermais do Sistema Aquífero Guarani no estado de São Paulo
}

\author{
Didier Gastmans ${ }^{1 *}$, Marcelo Martins Reis ${ }^{1}$, Chang Hung Kiang ${ }^{1}$
}

\begin{abstract}
Resumo Inúmeros geotermômetros vêm sendo utilizados para a determinação das temperaturas esperadas nos reservatórios de águas subterrâneas, sendo a maior parte deles baseada no equilíbrio químico existente entre as águas termais e minerais constituintes do arcabouço do aquífero. Nesse sentido, águas subterrâneas do Sistema Aquífero Guarani com temperaturas acima de $38^{\circ} \mathrm{C}$, classificadas como hipertermais pelo Código de Águas Minerais, tiveram sua composição química avaliada com o objetivo de se determinar as temperaturas esperadas no reservatório com base na utilização de diversos geotermômetros. Essas águas são essencialmente do tipo $\mathrm{Na}-\mathrm{HCO}_{3}$, passando a $\mathrm{Na}-\mathrm{HCO}_{3}-\mathrm{Cl}_{-} \mathrm{SO}_{4}$ devido ao aumento nas concentrações de sulfato e cloreto. Existe uma boa relação entre a temperatura e a profundidade em que se encontra o aquífero, indicando gradiente geotérmico médio de $27,7^{\circ} \mathrm{C} / \mathrm{km}$. Uma faixa na região central da área de estudo apresenta os menores gradientes termais, abaixo de $25^{\circ} \mathrm{C} / \mathrm{km}$, enquanto os maiores gradientes estão situados nas porções NE e W da área de estudo. Os geotermômetros de quartzo indicaram temperaturas acima das obtidas nas saídas dos poços, enquanto o geotermômetro de calcedônia avaliado mostrou temperaturas próximas das medidas em campo, com exceção de alguns poços em que os gradientes geotermais são menores. Os geotermômetros baseados no equilíbrio entre $\mathrm{Na} / \mathrm{K}$ retornaram temperaturas muito distintas das medidas, enquanto o geotermômetro baseado no equilíbrio entre sódio/potássio/cálcio obteve temperaturas próximas às registradas nos poços com temperaturas inferiores a $50^{\circ} \mathrm{C}$, em função do equilíbrio termodinâmico dessas águas com feldspatos. Os geotermômetros apontam para a possibilidade da ocorrência de misturas de águas mais profundas, especialmente nos poços da porção SW da área.
\end{abstract}

Palavras-chave: geotermômetros; hidroquímica; águas subterrâneas; Sistema Aquífero Guarani.

\begin{abstract}
Geothermometry of hyperthermal waters of Guarani Aquifer System of the state of São Paulo - Brazil. Several geothermometers have been employed to determine the expected temperature in the groundwater reservoirs, most part of them based on the chemical equilibrium between thermal groundwaters and minerals which constitute the aquifer framework. Based on this principle, groundwater from Guarani Aquifer System, which presents temperatures upon to $38^{\circ} \mathrm{C}$, classified as hyperthermal by the Brazilian Mineral Water Code, had their chemical composition evaluated with the main purpose to determine the expected temperatures in the reservoir based on the application of several geothermometers. These groundwaters can be classified as $\mathrm{Na}-\mathrm{HCO}_{3}$ type evolving to $\mathrm{Na}-\mathrm{HCO}_{3}-\mathrm{Cl}-\mathrm{SO}_{4}$ type due the increase in sulphate and chloride concentrations. Measured groundwater temperatures show a good correlation with the depth of the aquifer, indicating an average geothermal gradient of $27.7^{\circ} \mathrm{C} / \mathrm{km}$. The lowest geothermal gradients, bellow $25^{\circ} \mathrm{C} / \mathrm{km}$, are observed in the central portion of the study area; meanwhile the highest gradients are observed in NE and W portions of the study area. Quartz equilibrium based geothermometers return temperature over the measured temperatures, meanwhile chalcedony geothermometer returns temperatures near the measured in the wells, except for the wells located in the area which presents the lowest geothermal gradients. The geothermometers based on the equilibrium between $\mathrm{Na} / \mathrm{K}$ have returned temperatures diverse from the measured at the field, meanwhile the geothermometer based on the equilibrium between $\mathrm{Na} / \mathrm{K} / \mathrm{Ca}$ has presented good match with groundwater which present temperatures under $50^{\circ} \mathrm{C}$, due the thermodynamic equilibrium between these waters and feldspars. Geothermometers show evidences about mixtures between groundwaters from GAS and underlying units, especially in wells located in the SW portion of the study area.
\end{abstract}

Keywords: geothermometers; hydrochemistry; groundwater; Guarani Aquifer System.

\section{INTRODUÇÃO O aumento da temperatu-} ra na crosta terrestre com a profundidade, advindo do calor transferido das porções mais profundas e quentes localizadas no interior do planeta e do decaimento radioativo de isótopos com meia vida longa, é expresso pelo gradiente geotérmico. Esta forma de energia natural alcança a superfície do planeta de forma muito difusa. Entretanto, em diversas regiões do planeta, fontes potenciais de energia geotermal são encontradas a pequenas profundidades, associadas a ambientes e processos geológicos específicos, gerando gradientes geotermais anômalos.

Os geotermômetros representam importante ferramenta na exploração e estudo de sistemas

'Universidade Estadual Paulista - UNESP, Rio Claro (SP), Brasil. E-mails: gastmans@rc.unesp.br, geo-marcelo@hotmail.com, chang@rc.unesp.br

* Autor correspondente 
geotermais, podendo ser divididos em: geotermômetros qualitativos, que utilizam concentrações anômalas de diversos elementos indicativos, seja nas águas subterrâneas, nas águas superficiais ou no solo para a delimitação de áreas favoráveis à exploração do recurso geotermal, ou geotermômetros químicos quantitativos, que podem fornecer informações a respeito das temperaturas mínimas esperadas em subsuperfície, além de avaliar a possibilidade da ocorrência de misturas de águas advindas de fontes e com temperaturas distintas (Fournier, 1977).

A aplicação dos geotermômetros quantitativos está embasada no estudo da composição química de águas subterrâneas termais, com o objetivo de se avaliar o equilíbrio termodinâmico existente no reservatório, a partir da compreensão dos processos geoquímicos envolvidos na interação água-rocha. Estudos hidrogeoquímicos envolvendo geotermômetros vêm sendo conduzidos em diversos aquíferos onde ocorrências de águas termais são observadas, sejam de fontes naturais ou extraídas de poços, como, por exemplo, os realizados por Mazor et al. (1980), ProlLedesma (1991), D’Amore et al. (1987), Pirlo (2004), El-Fiky (2009), Dulanya et al. (2010) e Navarro et al. (2011), dentre outros.

Estudos apontam a existência na Bacia Sedimentar do Paraná de gradientes geotermais variando entre $10^{\circ} \mathrm{C} / \mathrm{km}$ e $40^{\circ} \mathrm{C} / \mathrm{km}$ (Uyeda \& Watanabe 1970, Meister 1973, Hamza et al. 1978, Gomes \& Hanza 2004), que afetam as águas subterrâneas do Sistema Aquífero Guarani (SAG), a mais importante unidade hidroestratigráfica da bacia e do continente sul-americano. Esse sistema, que ocupa área aproximada de 1,1 milhão de $\mathrm{km}^{2}$, estendendo-se por quatro países do Cone Sul (Argentina, Brasil, Paraguai e Uruguai), possui águas subterrâneas com temperaturas superiores a $35^{\circ} \mathrm{C}$, principalmente em sua zona confinada. Esse fato fez com que diversos autores apontassem a possibilidade da utilização de suas águas, principalmente em regiões onde o SAG situa-se a grandes profundidades, como fonte de energia geotermal de baixa entalpia (Chang 2001, Santos 2001, dentre outros).

O principal objetivo do presente estudo é avaliar a geotermometria das águas subterrâneas do SAG na porção Centro-Oeste do estado de São Paulo. Para tanto, foram selecionados poços cujas águas apresentam temperaturas que permitem sua classificação como hipertermais, de acordo com o enquadramento térmico dado às fontes de águas minerais, fixado pelo
Código de Águas Minerais (Brasil 1945). Essa norma jurídica define a existência de cinco classes de temperatura das fontes: fontes frias $\left(\mathrm{T}<25^{\circ} \mathrm{C}\right)$, fontes hipotermais $\left(25^{\circ} \mathrm{C}<\mathrm{T}<33^{\circ} \mathrm{C}\right)$, fontes mesotermais $\left(33^{\circ} \mathrm{C}<\mathrm{T}<36^{\circ} \mathrm{C}\right)$, fontes isotermais $\left(36^{\circ} \mathrm{C}<\mathrm{T}<38^{\circ} \mathrm{C}\right) \mathrm{e}$ fontes hipertermais $\left(\mathrm{T}>38^{\circ} \mathrm{C}\right)$.

\section{APLICAÇÃO DE GEOTERMÔMETROS}

Uma série de geotermômetros quantitativos foi desenvolvida ao longo dos últimos 40 anos possibilitando a estimativa rápida e eficiente das temperaturas nos aquíferos em estudos voltados à sua utilização como recurso geotermal. A aplicação desses geotermômetros está baseada nas condições de equilíbrio, dependentes da temperatura, estabelecidas entre um ou mais componentes da fase mineral e o fluido armazenado no reservatório (Pirlo 2004).

Segundo Fournier et al. (1974), para a aplicação desses geotermômetros, as seguintes premissas sintetizadas devem ser consideradas:

- as reações termodependentes, envolvendo o sistema água-rocha, controlam a quantidade das espécies indicadoras dissolvidas na água;

- é garantido um suprimento adequado de todos os reagentes;

- $\quad$ existe equilíbrio no reservatório em relação à reação de um indicador específico;

- não ocorre o reequilíbrio da espécie indicadora após a saída da água do reservatório;

- na ascensão da água não deve ocorrer mistura com outro reservatório e, se isso ocorrer, esse fenômeno deve ser passível de identificação e quantificação.

Os principais tipos de geotermômetros empregados na estimativa das temperaturas no reservatório são aqueles baseados na solubilidade da sílica (quartzo e pseudomorfos) e os embasados na capacidade de troca iônica entre cátions diversos. Recentemente foram desenvolvidos geotermômetros que avaliam, de forma simultânea, o equilíbrio existente para diversas espécies minerais.

Os geotermômetros de sílica foram inicialmente propostos por Fournier \& Rowe (1966), e baseiam-se na solubilidade do quartzo, sendo amplamente utilizados na predição das temperaturas de aquíferos, uma vez que o conteúdo de sílica de uma fonte termal está diretamente relacionado à última temperatura de equilíbrio do quartzo em seu interior. Segundo Fournier (1977), esses geotermômetros funcionam de maneira 
satisfatória para altas temperaturas (entre $150^{\circ} \mathrm{C}$ e $225^{\circ} \mathrm{C}$ ), uma vez que a temperaturas superiores ocorre a precipitação de sílica durante a ascensão da água, enquanto sob condições mais frias, outras espécies, como a calcedônia, a cristobalita ou a sílica amorfa, podem controlar a dissolução da sílica (Fournier \& Rowe 1966, Fournier \& Truesdell 1970, Arnórsson 1970, 1975).

Constantes de equilíbrio para reações de troca iônica ou de alteração mineral também são termodependentes e podem ser empregadas na definição das temperaturas de reservatórios geotermais (Founier 1977). Nessas reações, as relações entre os compostos dissolvidos são modificadas em função de alterações na temperatura de equilíbrio. As razões $\mathrm{Na} / \mathrm{K}$ são especialmente empregadas para águas subterrâneas naturais com temperaturas superiores a $200^{\circ} \mathrm{C}$, enquanto o geotermômetro Na-K-Ca (Fournier \& Truesdell 1973) possibilita cálculos mais acurados para águas mais frias (Fournier 1977).
A Tab. 1 lista os geotermômetros tradicionais utilizados nesse trabalho.

Reed \& Spycher (1984) descreveram um método, denominado multicomponente, que utiliza o equilíbrio entre diversas fases minerais e a água subterrânea para a determinação das temperaturas de equilíbrio no reservatório, permitindo que seja determinada a temperatura em que uma assembleia mineral encontra-se em equilíbrio entre si e com a fase aquosa. Essa técnica tem se mostrado bastante eficiente na predição do equilíbrio ou das temperaturas de reservatórios em diversas partes do globo (D'Amore et al. 1987, Tole et al. 1993, Pirlo 2004). Pang \& Reed (1998) refinaram essa técnica de maneira a corrigir problemas associados à determinação errônea, ou subestimada, das concentrações de alumínio em águas geotermais. Esses autores consideram que em determinado intervalo de temperatura do reservatório ocorre o equilíbrio termodinâmico para um ou mais minerais contendo alumínio.

Tabela 1 - Geotermômetros considerados no presente trabalho

\begin{tabular}{|c|c|c|}
\hline Geotermômetro - código & Equação & Referência \\
\hline Quartzo - Q1 & $\mathrm{T}_{\mathrm{SiO}_{2}}=\frac{1315}{5.205-\log \mathrm{SiO}_{2}}-273.15$ & Truesdell (1976) \\
\hline Quartzo - Q2 & $\mathrm{T}_{\mathrm{SiO}_{2}}=\frac{1309}{5.19-\log \mathrm{SiO}_{2}}-273.15$ & Fournier (1977) \\
\hline Quartzo - Q3 & $\mathrm{T}_{\mathrm{SiO}_{2}}=\left[\left(\frac{-1107}{\log \mathrm{SiO}_{2}}\right)+0.0254\right]-273.15$ & Rimstidt (1997) \\
\hline Quartzo - Q4 & $\left.\mathrm{T}_{\mathrm{SiO}_{2}}=-44.119+\left(0.24469 \mathrm{SiO}_{2}\right)+\left(\left(-1.7414 \times 10^{-4}\right) \mathrm{SiO}_{2}^{2}\right)+79.305 \times \log \mathrm{SiO}_{2}\right)$ & Verna \& Santoyo (1997) \\
\hline Calcedônia - Q5 & $\mathrm{T}_{\mathrm{SiO}_{2}}=\frac{1032}{4.69-\operatorname{logSiO} \mathrm{SiO}_{2}}-273.15$ & Fournier (1977) \\
\hline $\mathrm{Na} / \mathrm{K}-\mathrm{SP} 1$ & $\mathrm{~T}_{\mathrm{Na} / \mathrm{K}}=\frac{856}{\log (\mathrm{Na} / \mathrm{K})+0.857}-273.15$ & Truesdell (1976) \\
\hline $\mathrm{Na} / \mathrm{K}-\mathrm{SP} 2$ & $\mathrm{~T}_{\mathrm{Na} / \mathrm{K}}=\frac{1217}{\log (\mathrm{Na} / \mathrm{K})+1.483}-273.15$ & Fournier (1979) \\
\hline $\mathrm{Na} / \mathrm{K}-\mathrm{SP} 3$ & $\mathrm{~T}_{\mathrm{Na} / \mathrm{K}}=\frac{933}{\log (\mathrm{Na} / \mathrm{K})+0.993}-273.15$ & Arnorsson (1983) \\
\hline $\mathrm{Na} / \mathrm{K}-\mathrm{SP} 4$ & $\mathrm{~T}_{\mathrm{Na} / \mathrm{K}}=\frac{1390}{\log (\mathrm{Na} / \mathrm{K})+1.75}-273.15$ & Giggenbach(1988) \\
\hline $\mathrm{Na} / \mathrm{K}-\mathrm{SP} 5$ & $\mathrm{~T}_{\mathrm{Na} / \mathrm{K}}=\frac{1289}{\log (\mathrm{Na} / \mathrm{K})+1.615}-273.15$ & Verna \& Santoyo (1997) \\
\hline $\mathrm{Na} / \mathrm{K} / \mathrm{Ca}-\mathrm{SPC} 1 *$ & $\mathrm{~T}_{\mathrm{Na} / \mathrm{K} / \mathrm{Ca}}=\frac{1647}{\log (\mathrm{Na} / \mathrm{K})+\beta[\log (\sqrt{\mathrm{Ca}} / \mathrm{Na})+2.06]+2.47}-273.15$ & $\begin{array}{l}\text { Fournier \& Truesdell } \\
\qquad(1973)\end{array}$ \\
\hline
\end{tabular}

Todas as concentrações são expressas em $\mathrm{mg} / \mathrm{kg}$. $* \beta=4 / 3$ se $\mathrm{T}<100^{\circ} \mathrm{C}$ ou $\beta=1 / 3$ se $\mathrm{T}>100^{\circ} \mathrm{C}$. 


\section{CARACTERIZAÇÃO DA ÁREA DE ESTUDO}

A área de estudo abrange a porção Centro-Oeste do estado de São Paulo, situada entre os paralelos $20^{\circ} \mathrm{S}$ e $23^{\circ} 30^{\prime} \mathrm{S}$ e os meridianos $47 \mathrm{~W}^{\circ}$ e $52^{\circ} 30^{\prime} \mathrm{W}$, ocupando área aproximada de 150 mil km² (Fig. 1).

O clima dominante na maior parte da área de estudo, especialmente na porção central do estado de São Paulo, segundo a classificação de Köppen, é o do tipo Cwa, caracterizado como clima tropical de altitude, com verões chuvosos e invernos secos e temperaturas médias nos meses mais quentes em torno de $22^{\circ} \mathrm{C}$. Na região Noroeste do estado, o clima é classificado como do tipo $A w$ (tropical), com temperaturas médias superiores a $18^{\circ} \mathrm{C}$, também caracterizado por verões chuvosos e invernos secos (Setzer, 1966 in: São Paulo, 2005).

A área de afloramentos das unidades geológicas constituintes do SAG corta o estado de São Paulo como uma faixa de direção aproximada NNE-SSW, com cerca de 16 mil km² de extensão, que representa o limite leste da área de estudo. No restante da área, o aquífero encontra-se recoberto por basaltos da Formação Serra Geral e os arenitos do Grupo Bauru.
Importantes centros urbanos situados na porção Oeste do estado de São Paulo utilizam as águas subterrâneas do SAG para abastecimento público, além de outros usos relacionados principalmente à atividade agroindustrial, destacando-se os municípios de Ribeirão Preto, São José do Rio Preto, Bauru, São Carlos, Araraquara, Marília e Araçatuba, entre outros.

Sistema Aquífero Guarani Localizado no continente Sul-americano, o SAG representa um sistema aquífero transfronteiriço que se estende por cerca de 1 milhão de $\mathrm{km}^{2}$ em países que constituem o Cone Sul (Argentina, Brasil, Paraguai e Uruguai). Esta unidade hidrogeológica está associada ao conjunto de rochas sedimentares mesozoicas continentais siliciclásticas que ocorrem nas bacias sedimentares do Paraná, Chacoparanaense e Norte, com limites estratigráficos marcados por uma discordância regional permo-eotriássica em sua base e, no topo, pelos derrames basálticos da Formação Serra Geral. A geometria, compartimentação, arquitetura do preenchimento sedimentar e o fluxo no SAG são controlados pelos principais elementos estruturais dessas bacias:

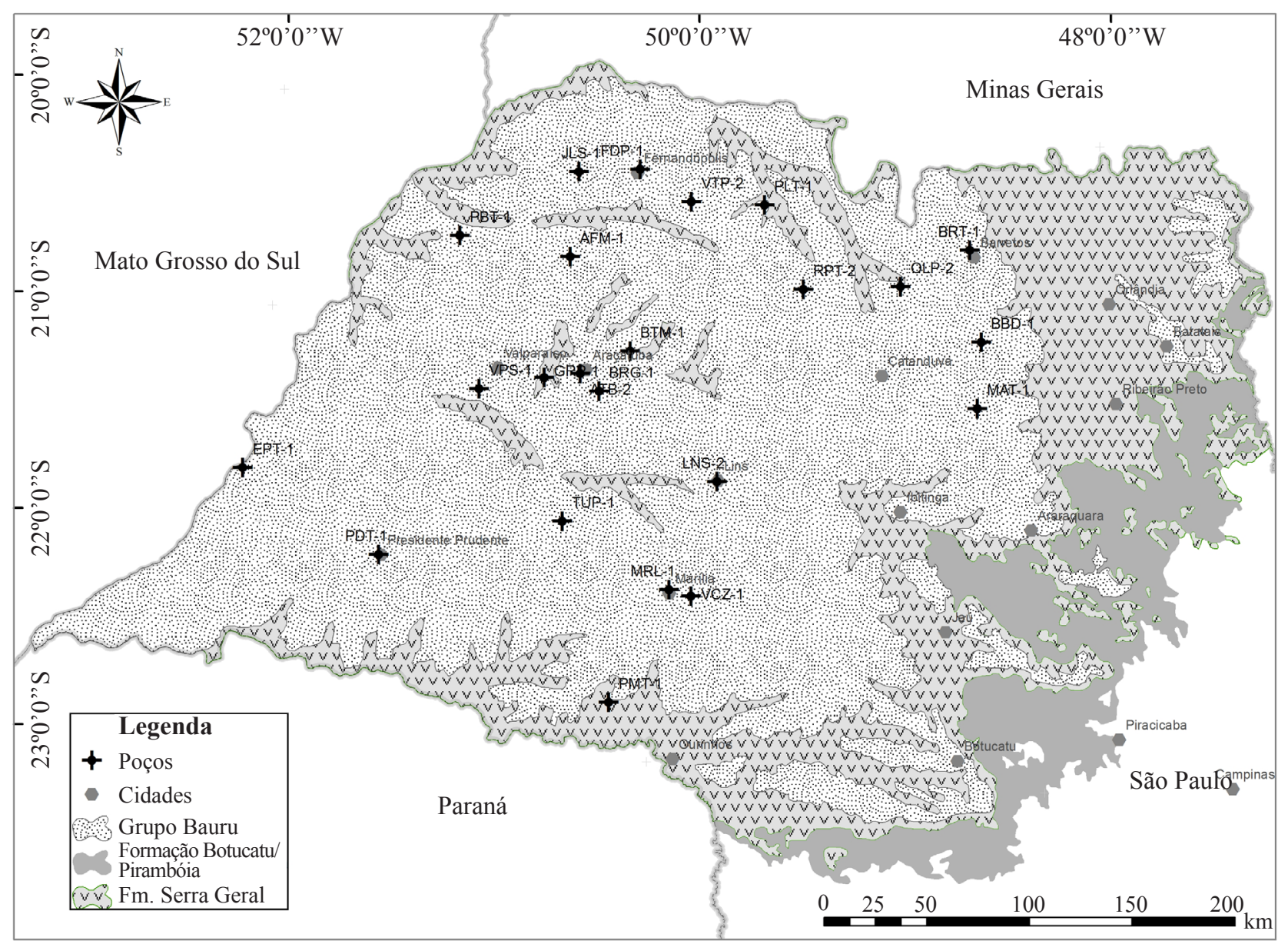

Figura 1 - Localização da área de estudo e dos poços amostrados. 
ao Norte, os arcos da Canastra e São Vicente; a Oeste, os arcos de Assunção e Pampeano/Puna; e, ao Sul, o Arco do Rio da Prata, além de importantes elementos estruturais reconhecidos no interior das bacias, como o Arco de Ponta Grossa, o Arco do Rio Grande e o Sinclinal de Torres (LEBAC 2008a, 2008b).

Aspectos geológicos A definição das unidades constituintes do SAG em toda sua extensão é tema controverso e, ao longo do tempo, unidades estratigráficas foram incorporadas ou retiradas do aquífero por vários autores (Rebouças 1976, Araújo et al. 1995, 1999, Campos 2000, LEBAC 2008a). Entretanto, no estado de São Paulo, o quadro estratigráfico da unidade é simples e existe consenso entre os autores, que associam ao aquífero nessa região às formações Botucatu e Pirambóia, de idade mesozoica (São Paulo 2005) (Fig. 1).

Os arenitos que constituem a Formação Pirambóia, unidade basal do SAG no estado de São Paulo, foram inicialmente reconhecidos por Washburne (1930) como a unidade basal do conjunto de arenitos sotopostos aos basaltos, com características eminentemente fluviais. Somente com os trabalhos de Soares $(1973,1975)$ na porção Norte da Bacia do Paraná, esses arenitos mesozoicos foram subdivididos em Formação Pirambóia (inferior) e Formação Botucatu (superior).

Segundo Caetano-Chang (1997), a Formação Pirambóia, na região Centro-Leste do estado de São Paulo, é composta predominantemente por fácies eólicas de dunas, interdunas (principalmente úmidas e, secundariamente, secas e aquáticas) e lençóis de areia, por vezes em interação com depósitos de canais fluviais e planícies de inundação. Segundo a autora, a unidade é formada por arenitos em geral finos a muito finos, subfeldspáticos, portadores de estratificações cruzadas de porte variável, em geral médio, e pacotes métricos sub-horizontais de arenitos muito finos, siltosos, em geral intensamente bioturbados, ou preservando laminações paralelas formadas pela migração de ôndulas eólicas. Na porção superior da unidade são reconhecidos depósitos de arenitos conglomeráticos de canais fluviais entrelaçados (Fácies Itirapina, de Caetano-Chang \& $\mathrm{Wu} 2006$ ), associados a depósitos eólicos de arenitos finos a médios, com estratificações cruzadas planares de pequeno porte.

Os arenitos da Formação Botucatu constituem uma delgada cobertura arenosa, mais ou menos contínua ao longo de toda a Bacia do Paraná. A unidade é formada por pacotes de arenitos finos a médios com coloração castanho-avermelhada, essencialmente quartzosos e bem arredondados. Apresentam sets de estratificações cruzadas com espessuras variando de $1,5 \mathrm{~m}$ a $10 \mathrm{~m}$ (РyT 2007), formadas por dunas eólicas em ambiente desértico. A Formação Botucatu sobrepõe-se à Formação Pirambóia, em contato discordante marcado por brusca mudança textural e de coloração.

São reconhecidos arenitos essencialmente quartzosos e arenitos subfeldspáticos como os principais litotipos para essas unidades, seja em superfície, seja em subsuperfície (França et al. 2003, Gesicki 2007), com conteúdos de feldspatos que variam de 5 a $10 \%$.

França et al. (2003) reconhecem a forte influência da circulação de águas meteóricas, extremamente agressivas, na geração de uma série de figuras diagenéticas relacionadas principalmente à dissolução de cimento carbonático e minerais constituintes do arcabouço dos arenitos, propondo um zoneamento no tipo de cimento presente: enquanto nas áreas de afloramento os arenitos possuem preponderantemente cimento constituído por calcedônia, no interior da bacia a presença de cimento carbonático, em percentagens superiores a $10 \%$, é observada.

Essa distribuição dos tipos de cimento estaria associada à evolução hidroquímica das águas do SAG, com a ocorrência de águas saturadas em calcedônia nas proximidades das áreas de recarga, enquanto na zona confinada do aquífero, a presença de cimento carbonático estaria associada à existência de águas saturadas em calcita (Gastmans et al. 2010). Segundo Gesicki (2007), a evolução diagenética dos arenitos da Formação Pirambóia no estado de São Paulo seria mais complexa que aquela dos arenitos da Formação Botucatu, devido principalmente à deposição anterior da unidade inferior, que teria sofrido efeitos relacionados à maior profundidade de soterramento, além da maior variabilidade mineralógica.

Hidrogeologia e hidroquímica As condições de fluxo das águas subterrâneas do SAG em sua porção setentrional, na qual está inserido o estado de São Paulo, são influenciadas pelas áreas de afloramento das unidades constituintes do aquífero, e que se encontram elevadas em relação às zonas onde o SAG está confinado (Silva 1983, Araújo et al. 1995, 1999, Gastmans et al. 2010). 
O fluxo das águas subterrâneas do SAG apresenta, a partir das zonas de afloramentos localizadas na porção central do estado de São Paulo (Fig. 1), direção aproximadamente EW, até o Rio Paraná. Entretanto, é reconhecido um trend regional que direciona o fluxo das águas subterrâneas do SAG de Norte para Sul, acompanhando o eixo da Bacia do Paraná, a partir da confluência entre os estados brasileiros do Paraná, São Paulo e Mato Grosso do Sul e o território paraguaio. Este padrão de fluxo é fortemente influenciado pelo quadro tectono-sedimentar da Bacia do Paraná, conforme já afirmado por Araújo et al. (1995, 1999), indicando, para o compartimento norte do aquífero, a influência exercida principalmente pelo Arco de Ponta Grossa, que atuaria como uma importante barreira ao fluxo.

São reconhecidos três tipos hidroquímicos para as águas do SAG no estado de São Paulo, cuja distribuição espacial está correlacionada à direção de fluxo das águas subterrâneas. Na região de afloramentos, as águas bicarbonatadas magnesianas e cálcio-magnesianas são predominantes; em direção a Oeste, ao longo de uma faixa de cerca de $60 \mathrm{~km}$ de largura, a partir do contato da zona de afloramentos das formações Pirambóia/Botucatu com os basaltos da Formação Serra Geral, as águas são bicarbonatadas cálcicas e cálcio-magnesianas; na porção de maior confinamento, localizada a Oeste da faixa de afloramentos, as águas tornam-se bicarbonatadas sódicas, evoluindo no extremo Sudoeste do estado para cloro-sulfatadas sódicas (Silva 1983).

Diversos processos geoquímicos podem ser associados a essa evolução, como dissolução e precipitação de cimento calcífero, dissolução de silicatos, troca iônica e mistura com águas provenientes de unidades subjacentes nas proximidades do eixo central da Bacia do Paraná (Silva 1983, Meng \& Maynard 2001, Sracek \& Hirata 2002, Bonotto 2006, Gastmans et al. 2010).

\section{Gradientes termais da Bacia do Paraná}

Estudos para a determinação dos gradientes térmicos na Bacia do Paraná tiveram início com a exploração petrolífera, uma vez que os processos de geração e maturação do óleo são termodependentes. Uyeda \& Watanabe (1970) apontaram valores que variam entre $14,2^{\circ} \mathrm{C} / \mathrm{km}$ e $19,2^{\circ} \mathrm{C} / \mathrm{km}$, o que levou esses autores a inferir que a Bacia do Paraná era relativamente fria.

Com o avanço da perfuração dos poços de petróleo na bacia, Meister (1973), utilizando informações provenientes de perfis de temperatura de 29 poços perfurados pela Petrobras, concluiu que a bacia é bastante fria, uma vez que apenas $8 \%$ dos poços apresentam gradientes termais superiores a $25^{\circ} \mathrm{C} /$ $\mathrm{km}$. A distribuição dos gradientes geotermais ao longo da bacia aponta para um crescimento de Norte para Sul, variando de $18^{\circ} \mathrm{C} / \mathrm{km}$ a $22^{\circ} \mathrm{C} / \mathrm{km}$, em São Paulo, para $30^{\circ} \mathrm{C} / \mathrm{km}$ a $42^{\circ} \mathrm{C} / \mathrm{km}$ no Rio Grande do Sul (Vitorello et al. 1978).

No estado de São Paulo, Gomes \& Hanza (2004), a partir da avaliação de dados provenientes de perfilagens em poços, apontaram a existência de gradientes termais entre $20^{\circ} \mathrm{C} / \mathrm{km}$ e $30^{\circ} \mathrm{C} / \mathrm{km}$, valores típicos de áreas continentais tectonicamente estáveis, com valores médios para a área da Bacia do Paraná de $22^{\circ} \mathrm{C} / \mathrm{km}$.

A relação entre a temperatura de surgência das águas do SAG e a profundidade do topo da unidade indica, no estado de São Paulo, valores aproximados de $26,6^{\circ} \mathrm{C} / \mathrm{km}$ (Teissedre \& Barner 1981), semelhante ao valor de $29^{\circ} \mathrm{C} / \mathrm{km}$ encontrado por Araújo et al. (1995) para toda a área de ocorrência do SAG. Estudos específicos realizados no Mato Grosso do Sul, Paraná e Uruguai apontam temperaturas semelhantes (Oleaga 2002, Gastmans 2007, Hindi 2007).

MATERIAIS E MÉTODOS Nos meses de outubro e novembro de 2009 e março de 2010 foram realizadas três campanhas de amostragem com vistas à caracterização hidroquímica das águas hipertemais do SAG no estado de São Paulo. Ao todo foram coletadas 23 amostras em poços, cuja localização pode ser visualizada na Fig. 1; os resultados analíticos são apresentados na Tab. 2.

Em campo, foram realizadas as medições da temperatura da água imediatamente na saída do poço, procurando-se manter o fluxo contínuo de água, de maneira a evitar o equilíbrio com a temperatura ambiente. As medidas de temperatura e condutividade foram feitas com condutivímetro da Marca Digimed, modelo DM-3P, acoplado a um eletrodo da mesma marca, modelo DMC-010M, com precisão de $0,1^{\circ} \mathrm{C}$ para as medidas de temperatura. $\mathrm{O} \mathrm{pH}$ também foi medido na saída do poços, com a utilização de $\mathrm{pH}$ metro da marca Digimed, modelo DM-2P, acoplado a um eletrodo da Marca Orion, modelo 9107BN, 115.

As amostras foram filtradas em campo imediatamente após a coleta, empregando-se filtro de membrana de acetato de celulose com abertura de $0,45 \mathrm{~mm}$, acondicionadas em frascos de 


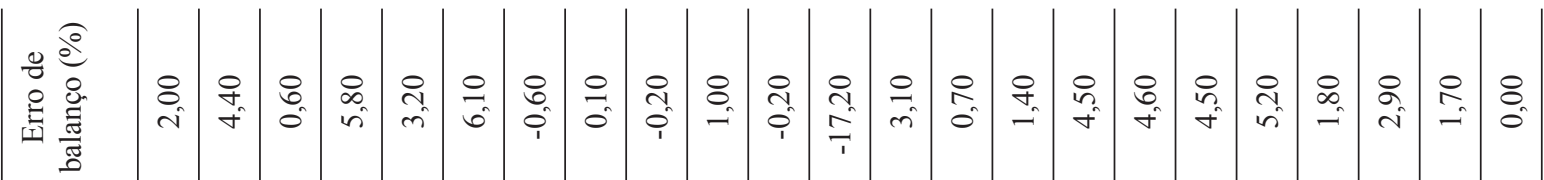

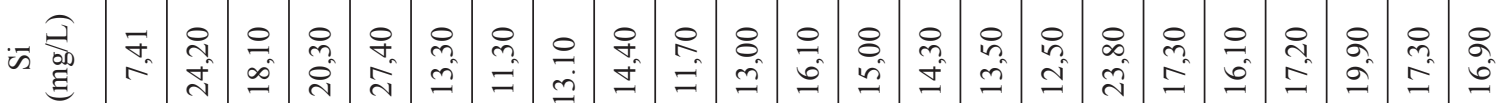

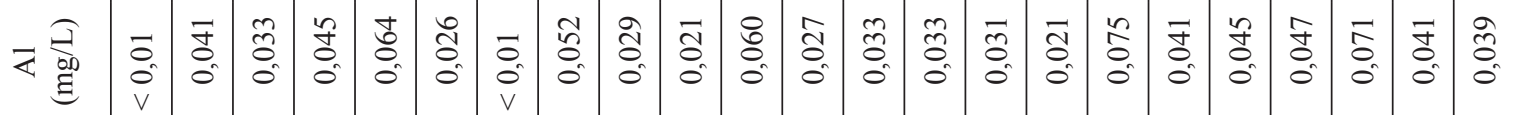

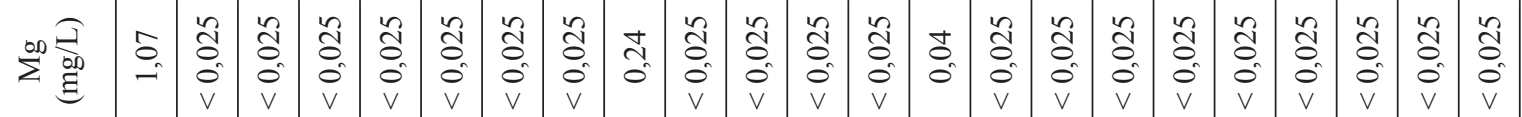

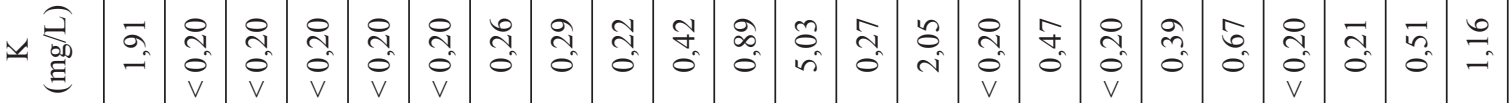

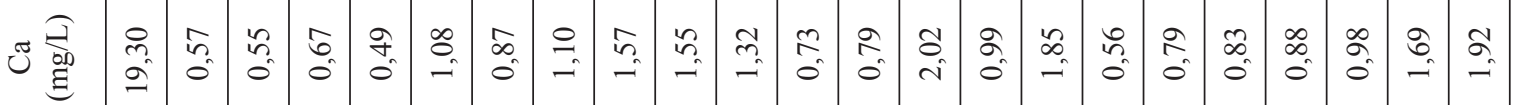

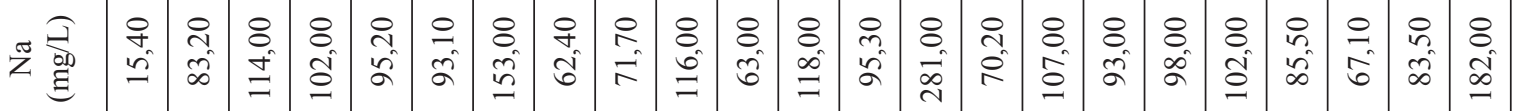

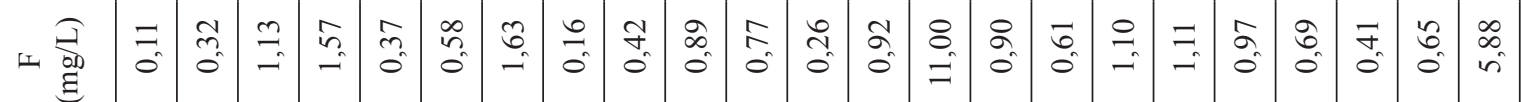

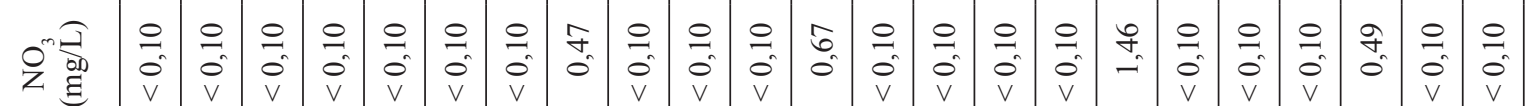

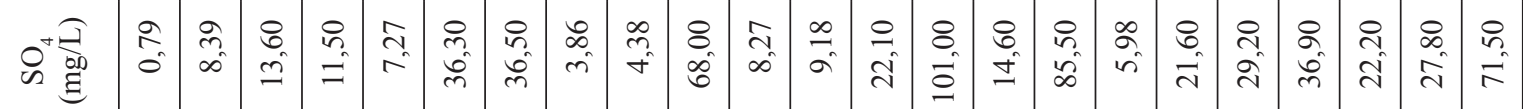

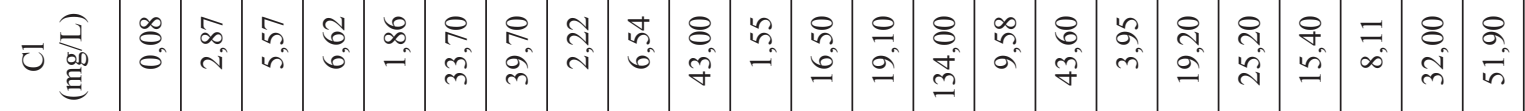

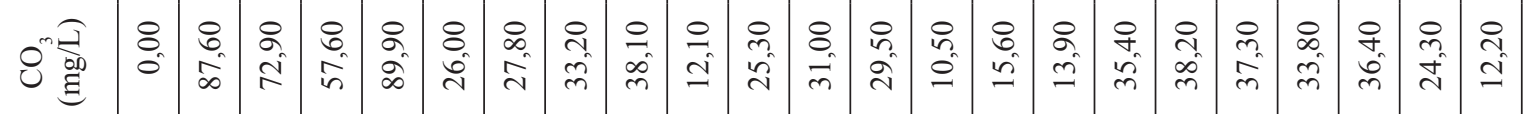

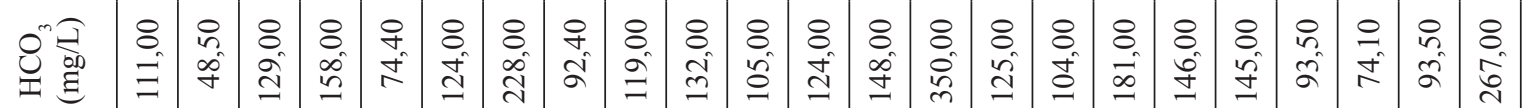

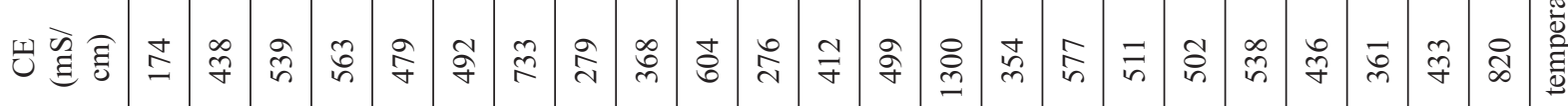

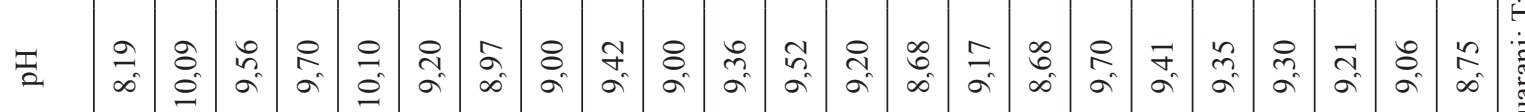

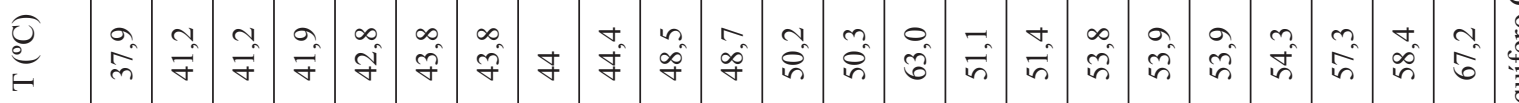

0
0
0
0
0
0
0
0
0
0
0
0
0
0
0
0
0
0
0

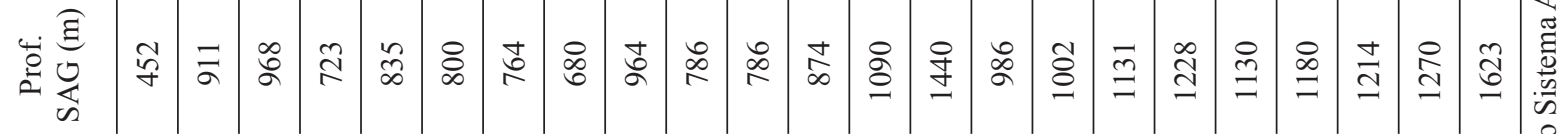

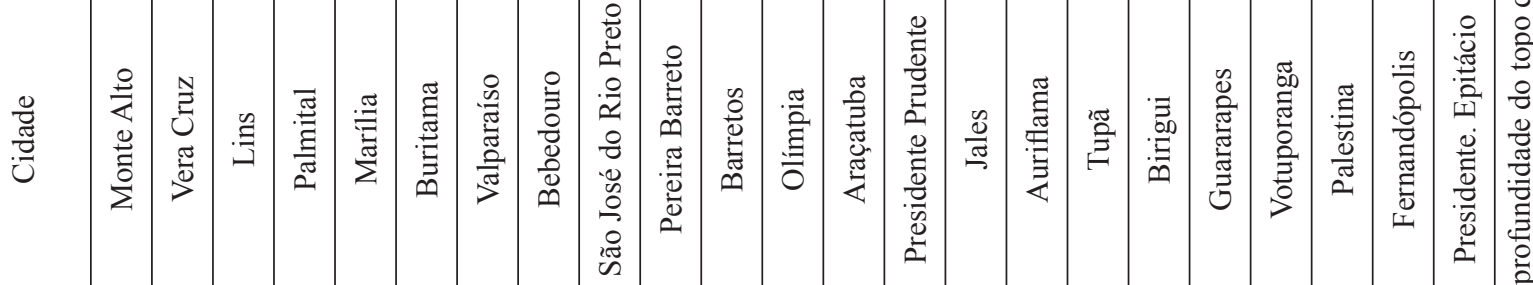

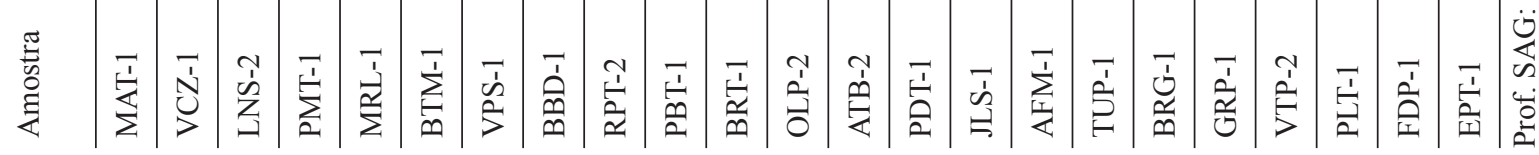


polipropileno e armazenadas sob refrigeração para envio ao laboratório. As amostras destinadas à determinação de cátions foram preservadas com ácido nítrico $3 \mathrm{~N}$.

A quantificação de cátions e ânions foi realizada no laboratório de hidrogeoquímica do Departamento de Geologia Aplicada da Universidade Estadual Paulista (UNESP), Campus de Rio Claro. Os ânions $\left(\mathrm{NO}_{3}, \mathrm{SO}_{4}, \mathrm{~F}, \mathrm{Cl}\right)$ e os cátions $(\mathrm{Na}, \mathrm{K})$ foram analisados por cromatografia de íons e a alcalinidade $\left(\mathrm{HCO}_{3}\right.$ e $\left.\mathrm{CO}_{3}\right)$ determinada por titulação, enquanto os cátions $(\mathrm{Ca}, \mathrm{Mg}, \mathrm{K}, \mathrm{Al}, \mathrm{Si})$ por Espectrometria de Emissão Atômica com fonte de Plasma de Argônio Indutivo (ICP-AES).

Os erros de balanço iônico foram calculados segundo a equação apresentada abaixo, que leva em consideração a relação existente entre as concentrações de cátions e ânions, expressas em miliequivalentes. Os resultados, apresentados na Tab. 2, indicam que os erros de balanço são inferiores a $5 \%$, exceto para a amostra OLP-02, que apresentou erro de $17 \%$, mas que, para os propósitos desse trabalho, pode ser utilizada.
Para o processamento geoquímico dos dados, como cálculo dos índices de saturação, atividades das espécies dissolvidas e simulações geoquímicas sob condição de equilíbrio químico com a caulinita, foi utilizado o software PHREEQC (Parkhurst \& Appelo, 1995), considerando para o equilíbrio inicial as temperaturas medidas em campo.

RESULTADOS As águas hipertermais do SAG apresentaram temperaturas que variam de 35,9 a $67,2^{\circ} \mathrm{C}$, respectivamente nas amostras MAT-01 e EPT-05, aumentando de E, onde estão localizadas as áreas de afloramento, em direção a SW. Outro incremento nas temperaturas pode ser observado de $\mathrm{N}$ para S-SW Esse aumento das temperaturas é concordante com o incremento na profundidade em que se encontra o topo da unidade (Figs. 2 e 3).

Os gradientes termais foram calculados com base no incremento de temperatura em relação à profundidade do topo do SAG para cada um dos poços (Tab. 3); sua distribuição é distinta quando comparada à do incremento das temperaturas. Observa-se diminuição do gradiente termal de Leste até a porção

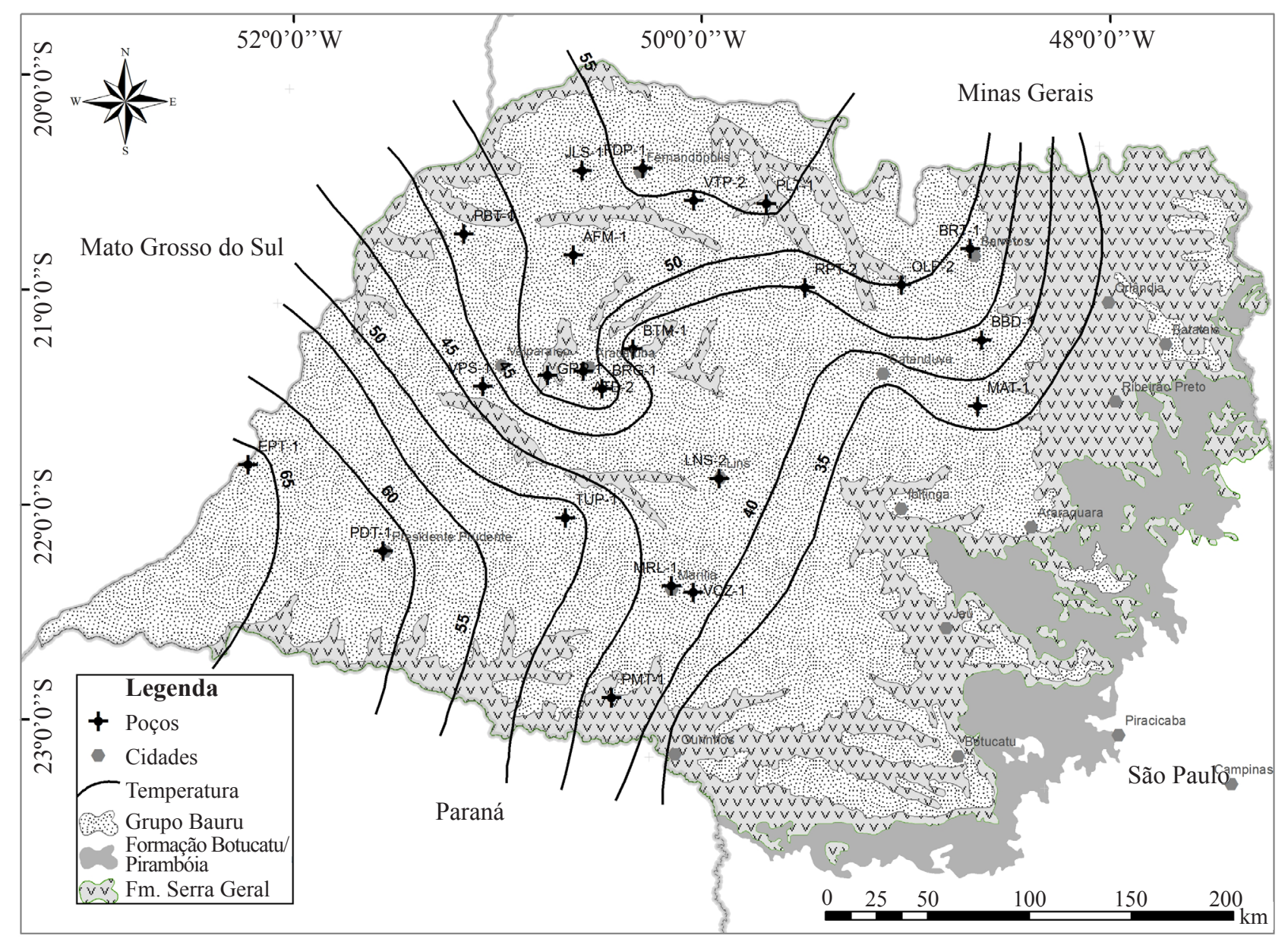

Figura 2-Mapa de isotermas. 
central da área de estudo, seguida de novo aumento em direção ao Rio Paraná (Fig. 4).

Caracterização hidrogeoquímica A composição das águas subterrâneas hipertermais do SAG permite sua classificação principalmente como bicarbonatadas sódicas e bicarbonatas cloretadas sulfatadas sódicas, em função do aumento das concentrações de cloreto e sulfato. Apenas a amostra MAT-01 é classificada como bicarbonatada cálcica (Fig. 5).

Os valores dos índices de saturação das águas em relação a uma série de minerais que constituem o arcabouço mineralógico do aquífero apontam que a maior parte das amostras está normalmente saturada em relação à calcita, pouco insaturadas em relação às espécies minerais relacionadas à sílica, como

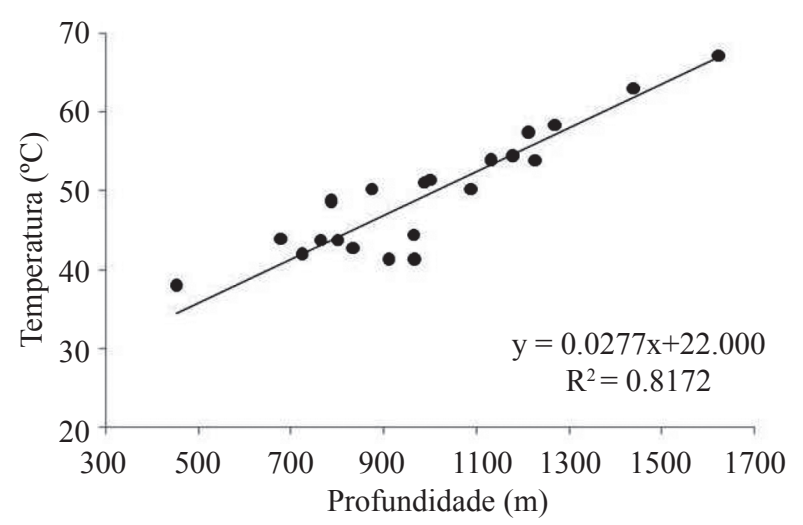

Figura 3 - Correlação entre a profundidade do topo do Sistema Aquífero Guarani e a temperatura da água subterrânea. quartzo e calcedônia, e insaturadas em relação aos alumossilicatos, como feldspatos, micas e argilominerais (Tab. 4).

Apesar das águas apresentarem índices de saturação negativos para argilominerais, os diagramas de estabilidade construídos para os sistemas Na$\mathrm{H}_{4} \mathrm{SiO}_{4}, \mathrm{Ca}-\mathrm{H}_{4} \mathrm{SiO}_{4}$, e K- $\mathrm{H}_{4} \mathrm{SiO}_{4}$ (Fig. 6) indicam que a maior parte das amostras coletadas encontra-se em equilíbrio com a caulinita e uma parte em equilíbrio termodinâmico com a muscovita. Esse equilíbrio em relação à caulinita será assumido na avaliação dos geotermômetros múltiplos.

Geotermômetros tradicionais As geotemperaturas das águas subterrâneas do SAG na área de estudo foram calculadas para cada um dos 11 geotermômetros (Tab. 1), e os resultados são apresentados na Tab. 5, juntamente com as temperaturas medidas na surgência. A comparação entre os dados obtidos pode ser visualizada nas Figs. 7 e 8, que mostram, respectivamente, as geotemperaturas calculadas para os geotermômetros de sílica e os provenientes das relações entre $\mathrm{Na} / \mathrm{K}$ e $\mathrm{Na} / \mathrm{K} / \mathrm{Ca}$.

Geotermômetros múltiplos A estimativa, por meio de modelos geoquímicos, do equilíbrio entre diversas fases minerais e águas de sistemas geotermais foi descrita inicialmente por Reed \& Spycher (1984), que, utilizando a composição química da água, estimaram a temperatura na qual a possível assembleia mineral que constitui o arcabouço do aquífero estaria em equilíbrio entre si e com a fase aquosa, e a

Tabela 3 - Gradientes termais calculados

\begin{tabular}{|c|c|c|c|c|c|c|c|c|c|}
\hline Amostra & Cidade & $\mathrm{T}\left({ }^{\circ} \mathrm{C}\right)$ & $\begin{array}{l}\text { Prof. topo } \\
\text { SAG (m) }\end{array}$ & $\begin{array}{l}\text { Gradiente } \\
\left({ }^{\circ} \mathrm{C} / \mathrm{km}\right)\end{array}$ & Amostra & Cidade & $\mathrm{T}\left({ }^{\circ} \mathrm{C}\right)$ & $\begin{array}{c}\text { Prof. topo } \\
\text { SAG (m) }\end{array}$ & $\begin{array}{l}\text { Gradiente } \\
\left({ }^{\circ} \mathrm{C} / \mathrm{km}\right)\end{array}$ \\
\hline MAT-1 & Monte Alto & 37,9 & 452,00 & 35,18 & ATB-2 & Araçatuba & 50,3 & 1090,00 & 25,96 \\
\hline VCZ-1 & Vera Cruz & 41,2 & 911,00 & 21,08 & PDT-1 & $\begin{array}{c}\text { Presidente } \\
\text { Prudente }\end{array}$ & 63,0 & 1440,00 & 28,47 \\
\hline LNS-2 & Lins & 41,2 & 968,00 & 19,83 & JLS-1 & Jales & 51,1 & 986,00 & 29,51 \\
\hline PMT-1 & Palmital & 41,9 & 723,00 & 27,52 & AFM-1 & Auriflama & 51,4 & 1002,00 & 29,34 \\
\hline MRL-1 & Marília & 42,8 & 835,00 & 24,91 & TUP-1 & Tupã & 53,8 & 1131,00 & 28,12 \\
\hline BTM-1 & Buritama & 43,8 & 800,00 & 27,25 & BRG-1 & Birigui & 53,9 & 1228,00 & 25,98 \\
\hline VPS-1 & Valparaíso & 43,8 & 764,00 & 28,53 & GRP-1 & Guararapes & 53,9 & 1130,00 & 28,23 \\
\hline BBD-1 & Bebedouro & 44,0 & 680,00 & 32,35 & VTP-2 & Votuporanga & 54,3 & 1180,00 & 27,37 \\
\hline RPT-2 & São José do Rio Preto & 44,4 & 964,00 & 23,24 & PLT-1 & Palestina & 57,3 & 1214,00 & 29,08 \\
\hline PBT-1 & Pereira Barreto & 48,5 & 786,00 & 33,72 & FDP-1 & Fernandópolis & 58,4 & 1270,00 & 28,66 \\
\hline BRT-1 & Barretos & 48,7 & 786,00 & 33,97 & EPT-1 & $\begin{array}{c}\text { Presidente } \\
\text { Epitácio } \\
\end{array}$ & 67,2 & 1623,00 & 27,85 \\
\hline OLP-2 & Olímpia & 50,2 & 874,00 & 32,27 & & & & & \\
\hline
\end{tabular}

T: temperatura; Prof. topo SAG: profundidade do topo do Sistema Aquífero Guarani. 


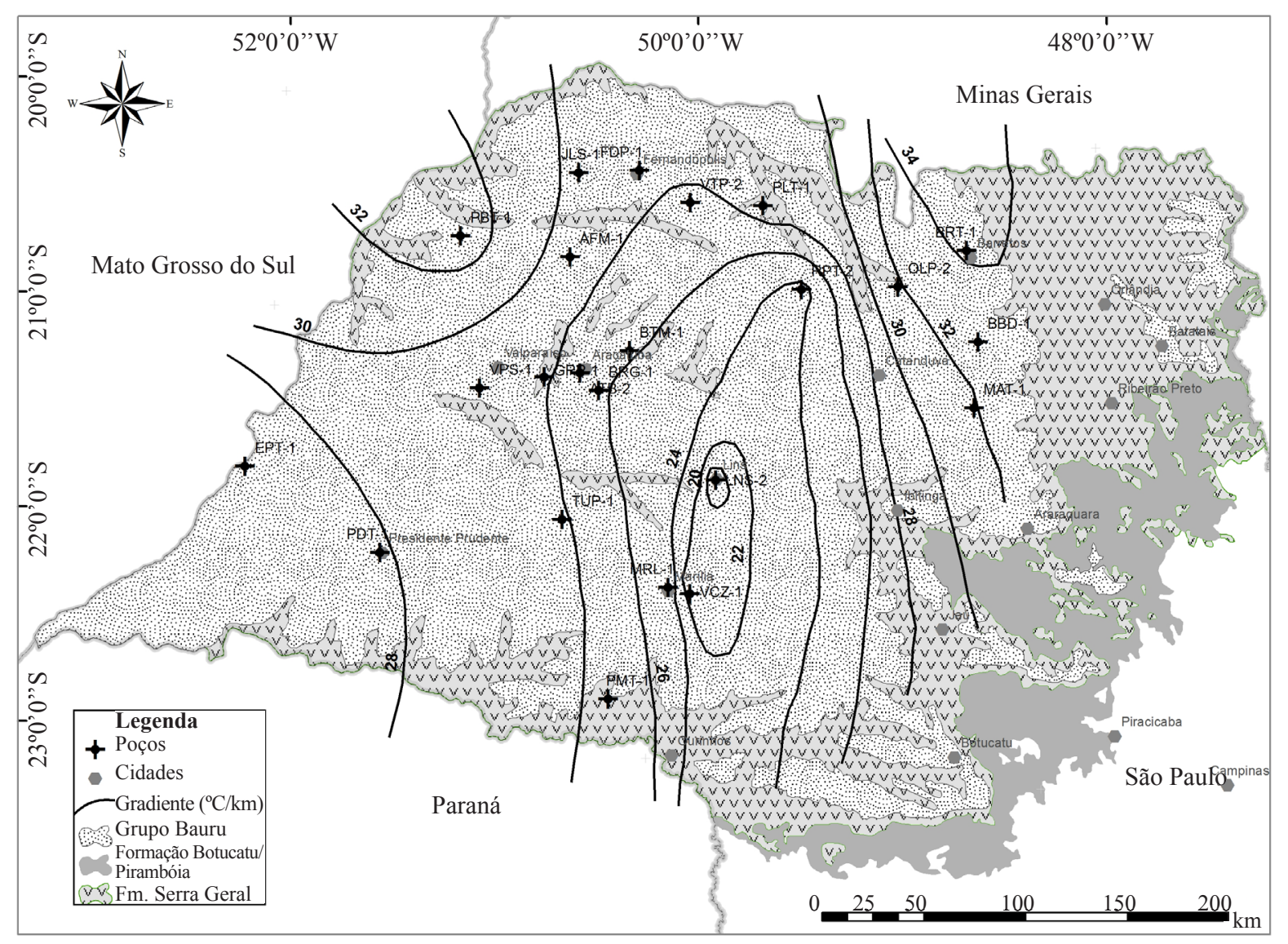

Figura 4-Distribuição dos gradientes termais.

Diagrama de Piper

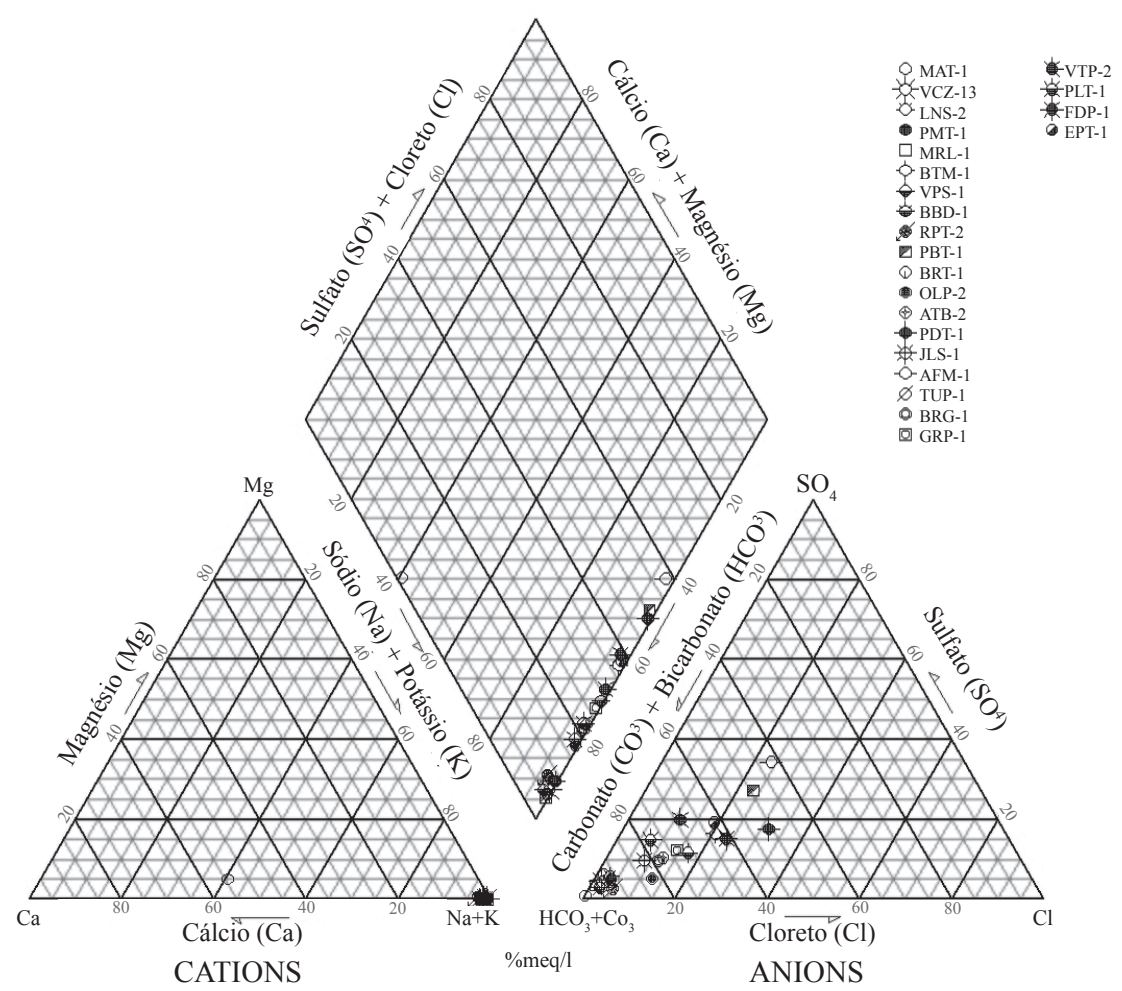

Figura 5 - Diagrama de Piper. 
Tabela 4 - Índices de saturação para as espécies minerais consideradas

\begin{tabular}{|c|c|c|c|c|c|c|c|c|c|c|c|}
\hline Amostra & Albita & Anortita & Calcita & Ca-Montmorilonita & Calcedônia & Caulinita & Clorita & Gibsita & Ilita & Mica-K & Quartzo \\
\hline MAT-1 & nc & $\mathrm{nc}$ & 0,39 & $\mathrm{nc}$ & $-0,52$ & $\mathrm{nc}$ & $\mathrm{nc}$ & $\mathrm{nc}$ & $\mathrm{nc}$ & $\mathrm{nc}$ & $-0,13$ \\
\hline VCZ-1 & $-3,37$ & $-5,70$ & 0,00 & $-6,61$ & $-0,65$ & $-3,87$ & 4,92 & $-2,11$ & $-6,21$ & $-2,35$ & $-0,27$ \\
\hline LNS-2 & $-2,71$ & $-5,52$ & $-0,02$ & $-5,02$ & $-0,44$ & $-2,59$ & 1,13 & $-1,68$ & $-5,07$ & $-0,96$ & $-0,06$ \\
\hline PMT-1 & $-2,76$ & $-5,30$ & 0,12 & $-5,18$ & $-0,48$ & $-2,74$ & 2,35 & $-1,71$ & $-5,13$ & $-1,03$ & $-0,10$ \\
\hline MRL-1 & $-3,13$ & $-5,42$ & $-0,02$ & $-6,30$ & $-0,64$ & $-3,62$ & 5,52 & $-2,00$ & $-5,88$ & $-1,94$ & $-0,26$ \\
\hline BTM-1 & $-3,05$ & $-5,39$ & 0,05 & $-4,82$ & $-0,47$ & $-2,36$ & $-1,25$ & $-1,53$ & $-5,18$ & $-0,93$ & $-0,10$ \\
\hline VPS-1 & $\mathrm{nc}$ & $\mathrm{nc}$ & $-0,04$ & $\mathrm{nc}$ & $-0,48$ & $\mathrm{nc}$ & $\mathrm{nc}$ & $\mathrm{nc}$ & $\mathrm{nc}$ & $\mathrm{nc}$ & $-0,11$ \\
\hline BBD-1 & $-2,78$ & $-4,59$ & $-0,08$ & $-3,53$ & $-0,42$ & $-1,27$ & $-1,67$ & $-1,03$ & $-3,96$ & 0,68 & $-0,05$ \\
\hline RPT-2 & $-3,29$ & $-5,28$ & 0,36 & $-5,37$ & $-0,52$ & $-2,85$ & 5,44 & $-1,72$ & $-5,29$ & $-1,40$ & $-0,15$ \\
\hline PBT-1 & $-3,37$ & $-5,58$ & 0,08 & $-5,26$ & $-0,53$ & $-2,67$ & $-2,50$ & $-1,62$ & $-5,58$ & $-1,21$ & $-0,17$ \\
\hline BRT-1 & $-3,38$ & $-4,88$ & 0,23 & $-5,20$ & $-0,61$ & $-2,62$ & 1,28 & $-1,52$ & $-5,00$ & $-0,44$ & $-0,25$ \\
\hline OLP-2 & $-3,54$ & $-5,95$ & 0,05 & $-6,56$ & $-0,62$ & $-3,78$ & 1,79 & $-2,09$ & $-5,73$ & $-1,26$ & $-0,26$ \\
\hline ATB-2 & $-3,22$ & $-5,48$ & 0,00 & $-5,31$ & $-0,51$ & $-2,76$ & $-0,13$ & $-1,69$ & $-5,53$ & $-1,32$ & $-0,15$ \\
\hline PDT-1 & $-2,49$ & $-4,95$ & 0,23 & $-3,90$ & $-0,41$ & $-1,56$ & $-3,67$ & $-1,19$ & $-4,07$ & 0,82 & $-0,05$ \\
\hline JLS-1 & $-3,52$ & $-5,47$ & 0,04 & $-5,52$ & $-0,55$ & $-2,90$ & $-0,22$ & $-1,71$ & $-5,83$ & $-1,67$ & $-0,20$ \\
\hline AFM-1 & $-3,31$ & $-5,36$ & $-0,13$ & $-4,65$ & $-0,48$ & $-2,15$ & $-4,33$ & $-1,41$ & $-5,20$ & $-0,67$ & $-0,13$ \\
\hline TUP-1 & $-3,28$ & $-5,33$ & 0,06 & $-6,22$ & $-0,61$ & $-3,53$ & 4,26 & $-1,97$ & $-6,05$ & $-2,06$ & $-0,26$ \\
\hline BRG-1 & $-3,44$ & $-5,55$ & 0,10 & $-6,12$ & $-0,59$ & $-3,43$ & 1,86 & $-1,94$ & $-6,04$ & $-1,91$ & $-0,24$ \\
\hline GRP-1 & $-3,39$ & $-5,44$ & 0,10 & $-5,91$ & $-0,59$ & $-3,42$ & 1,48 & $-1,84$ & $-5,74$ & $-1,45$ & $-0,24$ \\
\hline VTP-2 & $-3,31$ & $-5,20$ & 0,01 & $-5,61$ & $-0,54$ & $-3,03$ & 1,54 & $-1,79$ & $-5,81$ & $-1,71$ & $-0,20$ \\
\hline PLT-1 & $-3,12$ & $-4,64$ & 0,01 & $-5,02$ & $-0,48$ & $-2,60$ & 2,05 & $-1,63$ & $-5,27$ & $-1,08$ & $-0,14$ \\
\hline FDP-1 & $-3,36$ & $-4,93$ & 0,18 & $-5,41$ & $-0,50$ & $-2,91$ & 0,47 & $-1,76$ & $-5,58$ & $-1,30$ & $-0,17$ \\
\hline EPT-1 & $-3,38$ & $-5,18$ & 0,32 & $-5,71$ & $-0,54$ & $-3,07$ & $-1,35$ & $-1,80$ & $-5,88$ & $-1,40$ & $-0,22$ \\
\hline
\end{tabular}

Nc: não calculado em função da determinação da concentração de alumínio.
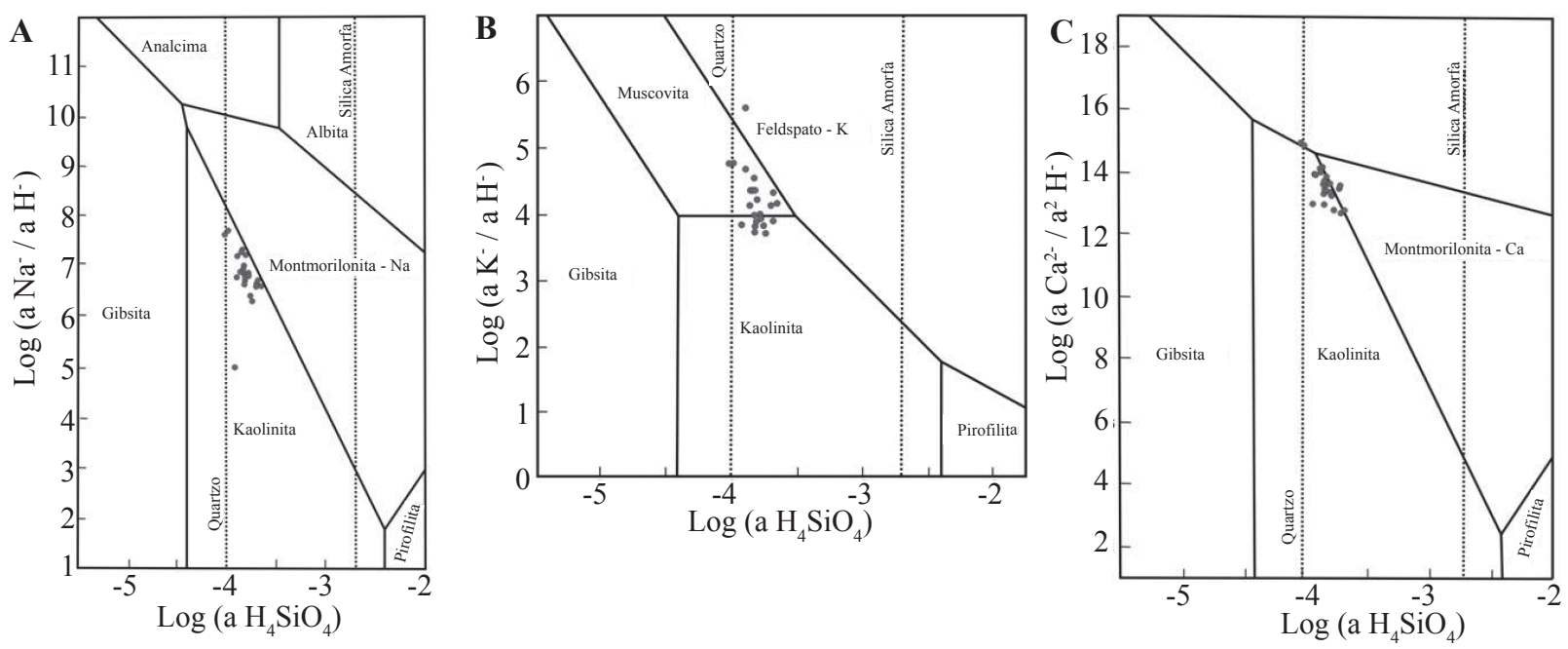

Figura 6-Diagramas de estabilidade - (A) Sistema Na- $\mathrm{H}_{4} \mathrm{SiO}_{4}$; (B) Sistema $\mathrm{K}_{-} \mathrm{H}_{4} \mathrm{SiO}_{4}$; (C) Sistema $\mathrm{Ca}_{-} \mathrm{H}_{4} \mathrm{SiO}_{4}$.

aplicação dessa técnica em diversos sistemas geotermais se mostrou importante na determinação do status do equilíbrio do sistema, fornecendo informações importantes em relação à temperatura de equilíbrio ou do próprio reservatório (D'Amore et al. 1987, Tole et al. 1993, Pirlo 2004).

$\mathrm{O}$ equilíbrio existente na temperatura do reservatório entre as águas hipertermais do SAG e a caulinita (Fig. 6) constituiu a premissa da simulação geoquímica para se determinar, inicialmente, as concentrações de alumínio nas águas, uma vez que em algumas amostras as concentrações encontram-se abaixo dos limites de detecção, e possibilitar a predição das temperaturas de equilíbrio para uma assembleia mineral possivelmente presente nas rochas que constituem o reservatório, uma vez que, segundo Pang \& Reed (1998), a determinação das concentrações desse elemento nas águas subterrâneas representa uma dificuldade para o estabelecimento de modelos geoquímicos envolvendo alumosilicatos. 
Tabela 5 - Geotemperaturas obtidas a partir dos geotermômetros avaliados

\begin{tabular}{|c|c|c|c|c|c|c|c|c|c|c|c|c|}
\hline \multirow{2}{*}{ Amostra } & \multirow{2}{*}{$\mathrm{T}\left({ }^{\circ} \mathrm{C}\right)$} & \multicolumn{11}{|c|}{ Geotermômetros } \\
\hline & & Q1 & Q2 & Q3 & Q4 & Q5 & SP1 & $\mathrm{SP} 2$ & SP3 & SP4 & SP5 & SPC1 \\
\hline MAT-1 & 37,9 & 55,3 & 55,0 & 36,3 & 55,0 & 22,6 & 212,3 & 236,2 & 218,0 & 250,1 & 238,1 & 32,0 \\
\hline VCZ-1 & 41,2 & 103,6 & 103,5 & 88,2 & 104,1 & 73,7 & $-35,4$ & 14,8 & $-23,5$ & 36,1 & 22,6 & 41,3 \\
\hline LNS-2 & 41,2 & 90,5 & 90,3 & 74,0 & 91,1 & 59,6 & $-44,1$ & 5,7 & $-32,3$ & 27,0 & 13,6 & 44,7 \\
\hline PMT-1 & 41,9 & 95,6 & 95,4 & 79,5 & 96,1 & 65,0 & $-41,1$ & 8,9 & $-29,3$ & 30,2 & 16,7 & 40,3 \\
\hline MRL-1 & 42,8 & 109,5 & 109,5 & 94,7 & 109,9 & 80,1 & $-39,2$ & 10,8 & $-27,3$ & 32,2 & 18,6 & 45,1 \\
\hline BTM-1 & 43,8 & 77,5 & 77,3 & 60,0 & 78,1 & 45,8 & $-38,6$ & 11,5 & $-26,7$ & 32,8 & 19,3 & 31,5 \\
\hline VPS-1 & 43,8 & 71,0 & 70,8 & 53,0 & 71,5 & 39,0 & $-37,1$ & 13,0 & $-25,2$ & 34,4 & 20,8 & 54,1 \\
\hline BBD-1 & 44,0 & 76,9 & 76,7 & 59,3 & 77,5 & 45,2 & $-4,8$ & 45,8 & 7,4 & 67,3 & 53,4 & 44,6 \\
\hline RPT-2 & 44,4 & 80,8 & 80,6 & 63,5 & 81,4 & 49,3 & $-19,2$ & 31,4 & $-7,0$ & 52,9 & 39,1 & 32,6 \\
\hline PBT-1 & 48,5 & 72,4 & 72,2 & 54,5 & 72,9 & 40,4 & $-13,6$ & 37,0 & $-1,5$ & 58,5 & 44,6 & 54,1 \\
\hline BRT-1 & 48,7 & 76,6 & 76,4 & 59,0 & 77,2 & 44,9 & 43,1 & 92,0 & 55,0 & 113,0 & 98,9 & 73,7 \\
\hline OLP-2 & 50,2 & 85,4 & 85,3 & 68,5 & 86,1 & 54,2 & 111,2 & 153,4 & 121,6 & 172,3 & 158,6 & 168,0 \\
\hline ATB-2 & 50,3 & 82,5 & 82,3 & 65,3 & 83,1 & 51,1 & $-21,7$ & 28,8 & $-9,6$ & 50,3 & 36,5 & 52,5 \\
\hline PDT-1 & 63,0 & 80,5 & 80,3 & 63,2 & 81,1 & 49,0 & 12,8 & 63,0 & 24,9 & 84,5 & 70,4 & 110,6 \\
\hline JLS-1 & 51,1 & 78,1 & 77,9 & 60,6 & 78,7 & 46,5 & $-30,5$ & 19,9 & $-18,5$ & 41,3 & 27,6 & 30,6 \\
\hline AFM-1 & 51,4 & 75,0 & 74,8 & 57,3 & 75,6 & 43,2 & $-6,8$ & 43,8 & 5,3 & 65,3 & 51,3 & 53,2 \\
\hline TUP-1 & 53,8 & 102,8 & 102,7 & 87,4 & 103,3 & 72,9 & $-38,6$ & 11,5 & $-26,7$ & 32,9 & 19,3 & 42,6 \\
\hline BRG-1 & 53,9 & 88,5 & 88,4 & 71,8 & 89,1 & 57,5 & $-10,3$ & 40,3 & 1,8 & 61,8 & 47,9 & 63,4 \\
\hline GRP-1 & 53,9 & 85,4 & 85,3 & 68,5 & 86,1 & 54,2 & 8,5 & 58,9 & 20,7 & 80,3 & 66,3 & 79,7 \\
\hline VTP-2 & 54,3 & 88,3 & 88,1 & 71,6 & 88,9 & 57,3 & $-36,2$ & 14,0 & $-24,3$ & 35,3 & 21,8 & 34,2 \\
\hline PLT-1 & 57,3 & 94,7 & 94,5 & 78,5 & 95,3 & 64,1 & $-18,5$ & 32,1 & $-6,4$ & 53,6 & 39,8 & 38,8 \\
\hline FDP-1 & 58,4 & 88,5 & 88,4 & 71,8 & 89,1 & 57,5 & 5,6 & 56,0 & 17,8 & 77,5 & 63,5 & 54,9 \\
\hline EPT-1 & 67,2 & 87,5 & 87,3 & 70,7 & 88,1 & 56,4 & 7,3 & 57,7 & 19,5 & 79,1 & 65,1 & 85,9 \\
\hline
\end{tabular}

T: temperatura $\left({ }^{\circ} \mathrm{C}\right)$.

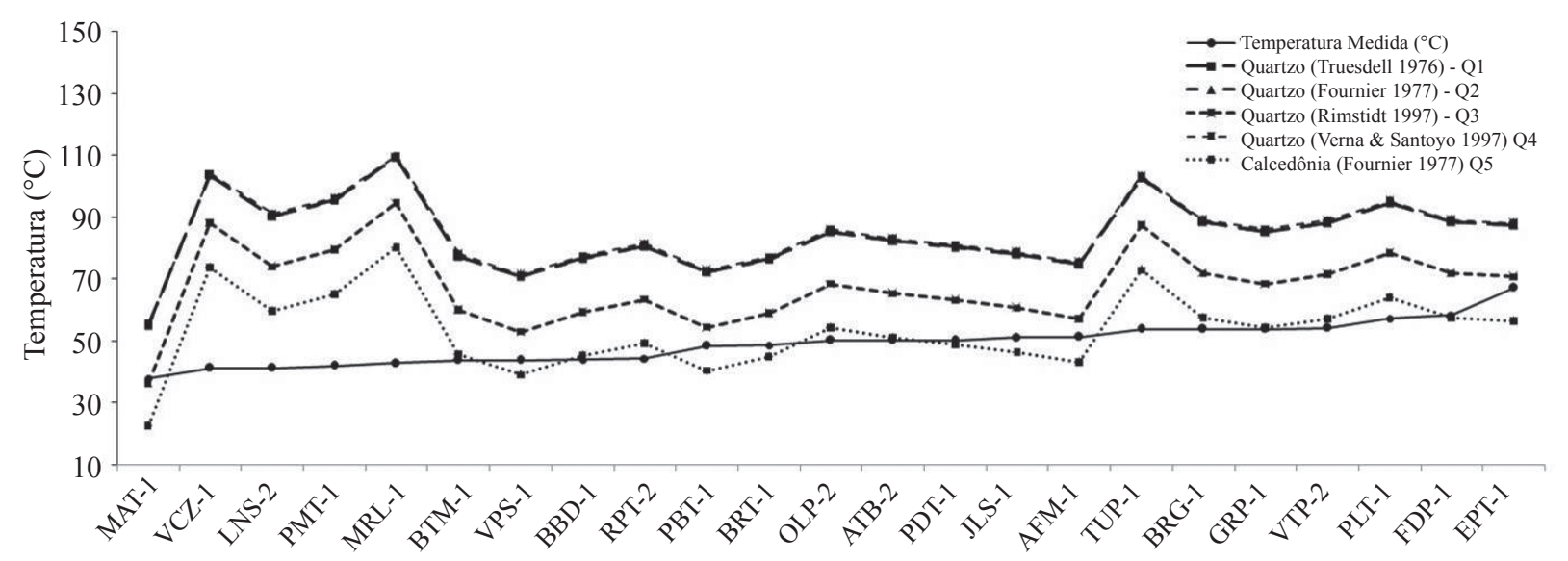

Figura 7 - Comparação entre as temperaturas medidas nos poços e as calculadas para cada um dos geotermômetros de sílica considerados neste estudo. Os poços estão ordenados segundo as suas temperaturas.

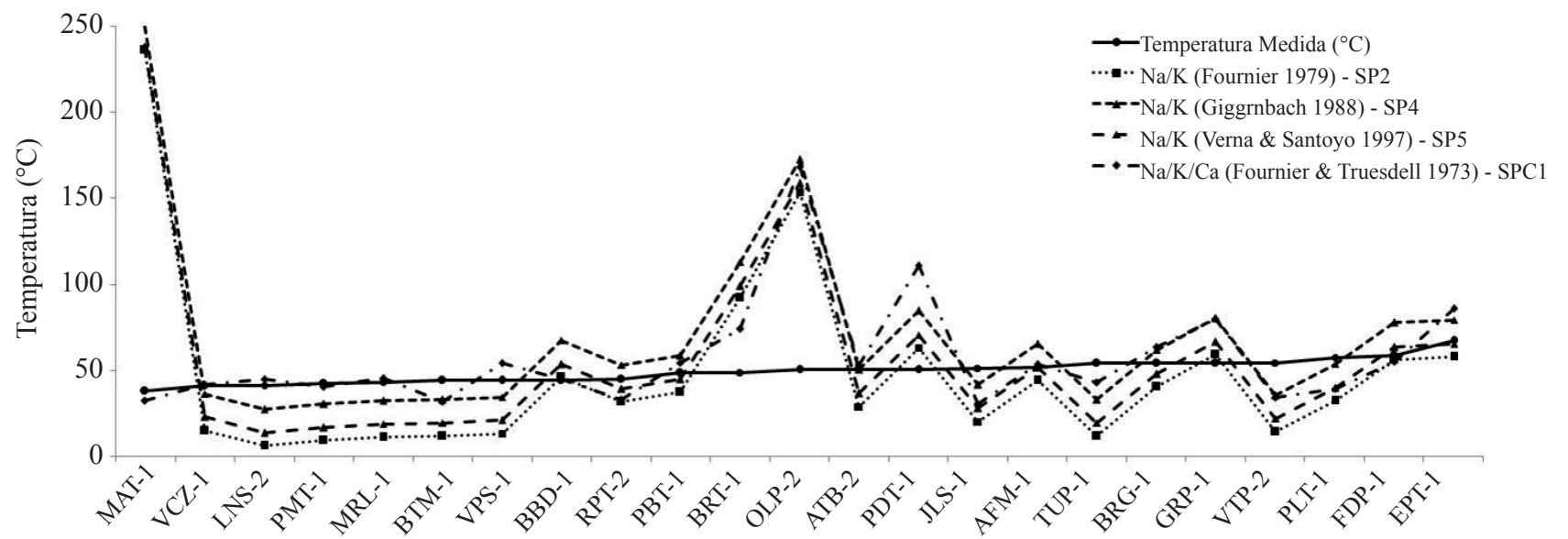

Figura 8 - Comparação entre as temperaturas medidas nos poços e as calculadas para cada um dos geotermômetros de cátions considerados neste estudo. Os poços estão ordenados segundo as suas temperaturas. 
As simulações conduzidas no software PHREEQC (Parkhurst \& Appelo 1995) consideraram temperaturas entre $20^{\circ} \mathrm{C}$ e $100^{\circ} \mathrm{C}$. Posteriormente, para cada amostra de água foi construído gráfico correlacionando os índices de saturação (IS) e a temperatura, como exemplificado na Fig. 9.

A interpretação de geotemperaturas por componentes múltiplos está baseada na definição da temperatura na qual os índices de saturação

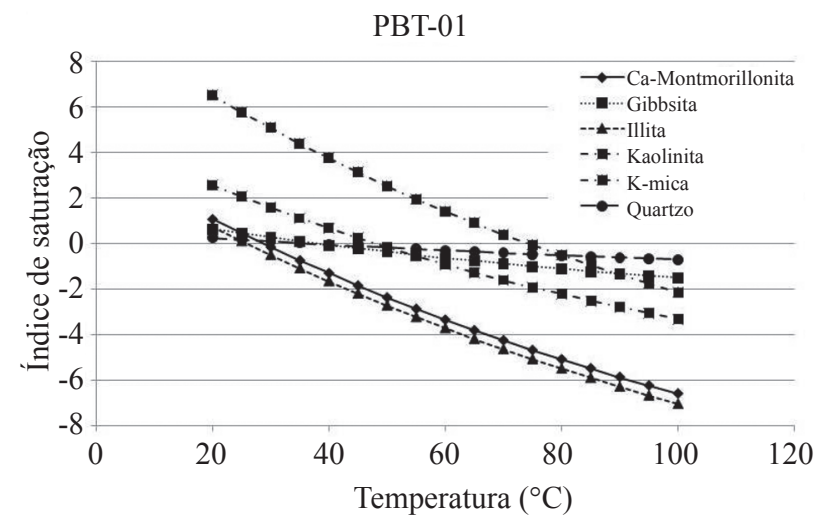

Figura 9 - Variação dos índices de saturação em função da temperatura para as espécies minerais silicáticas consideradas no presente estudo. $O$ gráfico se refere à amostra PBT-01, cuja temperatura medida foi de $48,5^{\circ} \mathrm{C}$. para uma determinada assembleia selecionada mineral é zero. Como a interpretação dos resultados é carregada de subjetividade, principalmente devido à assembleia mineral selecionada, escolheu-se um conjunto de minerais possivelmente presentes dentro do arcabouço mineralógico do aquífero, conforme descrito em estudos petrográficos realizados por Gastmans (2007), Gastmans et al. (2010) e Hirata et al. (2011). As temperaturas obtidas para essa assembleia mineral são apresentadas na Tab. 6.

DISCUSSÃO O incremento das temperaturas das águas subterrâneas do SAG está diretamente relacionado à profundidade em que se encontra o topo da unidade, conforme observado em estudos anteriores por Teissedre \& Barner (1981) e Silva (1983). O gradiente termal médio obtido no presente estudo, de $27,7^{\circ} \mathrm{C} / \mathrm{km}$, considerando-se a temperatura média anual na superfície de $22^{\circ} \mathrm{C}$, é semelhante ao encontrado pelos autores citados. A avaliação individual dos gradientes calculados para cada um dos poços mostra variação de valores que vai de $19,8^{\circ} \mathrm{C} / \mathrm{km}$ na cidade de Lins a $35,2^{\circ} \mathrm{C} /$ $\mathrm{km}$ em Monte Alto, com média de $28,2^{\circ} \mathrm{C} / \mathrm{km}$, um

Tabela 6 - Geotemperaturas derivadas do índice de saturação para cada uma das espécies da assembleia mineral considerada nesse estudo

\begin{tabular}{lcccccccrc}
\hline Amostra & \multirow{2}{*}{$\left({ }^{\circ} \mathrm{C}\right)$} & Ca-Mont & Gibsita & Ilita & Caulinita & K-Mica & Quartzo & Calcedônia & $\begin{array}{c}\text { Temperatura } \\
\text { Média }\left(\mathrm{C}^{\circ}\right)\end{array}$ \\
\hline MAT-1 & 37,9 & 18,8 & 29,0 & 15,5 & 38,0 & 58,1 & 29,3 & 5,1 & $27,7 \pm 17,2$ \\
\hline VCZ-1 & 41,2 & 20,7 & 30,0 & 24,4 & 41,4 & 79,8 & 29,4 & $-10,2$ & $30,8 \pm 26,9$ \\
\hline LNS-2 & 41,2 & 24,3 & 28,3 & 24,1 & 41,1 & 67,2 & 39,5 & 9,2 & $33,4 \pm 18,3$ \\
\hline PMT-1 & 41,9 & 25,1 & 29,5 & 25,3 & 41,9 & 69,8 & 38,1 & 8,5 & $34,0 \pm 19,1$ \\
\hline MRL-1 & 42,8 & 22,6 & 31,1 & 26,5 & 43,0 & 82,1 & 31,7 & 6,9 & $34,8 \pm 23,5$ \\
\hline BTM-1 & 43,8 & 26,0 & 32,0 & 22,8 & 43,8 & 67,0 & 41,8 & 7,7 & $34,4 \pm 18,8$ \\
\hline VPS-1 & 43,8 & 25,1 & 32,8 & 21,2 & 43,8 & 65,1 & 36,9 & 5,7 & $32,9 \pm 18,8$ \\
\hline BBD-1 & 44,0 & 26,1 & 31,4 & 22,5 & 44,1 & 66,8 & 41,8 & 9,6 & $34,6 \pm 18,4$ \\
\hline RPT-2 & 44,4 & 27,0 & 33,4 & 27,1 & 44,4 & 71,0 & 37,3 & 6,6 & $35,2 \pm 19,7$ \\
\hline PBT-1 & 48,5 & 28,8 & 38,3 & 25,9 & 48,2 & 73,9 & 37,3 & 5,1 & $36,8 \pm 21,2$ \\
\hline BRT-1 & 48,7 & 30,0 & 39,0 & 31,2 & 48,7 & 82,9 & 36,6 & 5,6 & $39,1 \pm 23,4$ \\
\hline OLP-2 & 50,2 & 31,1 & 39,7 & 38,0 & 49,6 & 101,3 & 38,4 & 7,1 & $43,6 \pm 23,0$ \\
\hline ATB-2 & 50,3 & 31,8 & 38,7 & 29,6 & 50,5 & 76,9 & 42,2 & 11,7 & $40,2 \pm 20,2$ \\
\hline PDT-1 & 50,3 & 31,5 & 36,8 & 29,9 & 50,4 & 80,5 & 47,1 & 14,9 & $41,6 \pm 20,8$ \\
\hline JLS-1 & 51,1 & 31,7 & 40,4 & 29,0 & 51,2 & 77,0 & 40,2 & 9,4 & $39,9 \pm 20,9$ \\
\hline AFM-1 & 51,4 & 31,8 & 39,9 & 26,9 & 51,5 & 75,6 & 43,0 & 10,8 & $39,9 \pm 20,4$ \\
\hline TUP-1 & 53,8 & 35,1 & 41,8 & 35,9 & 53,7 & 89,4 & 44,4 & 13,1 & $44,8 \pm 23,3$ \\
\hline BRG-1 & 53,9 & 35,1 & 42,6 & 35,2 & 53,9 & 88,0 & 43,2 & 12,6 & $44,4 \pm 23,0$ \\
\hline GRP-1 & 53,9 & 34,9 & 43,0 & 35,8 & 54,0 & 89,6 & 42,8 & 11,9 & $44,6 \pm 23,7$ \\
\hline VTP-2 & 54,3 & 35,2 & 42,0 & 33,0 & 54,2 & 84,2 & 45,7 & 13,5 & $44,0 \pm 21,8$ \\
\hline PLT-1 & 57,3 & 36,9 & 43,2 & 35,6 & 57,4 & 87,7 & 50,2 & 19,2 & $47,2 \pm 21,2$ \\
\hline FDP-1 & 58,4 & 39,1 & 45,4 & 37,1 & 58,5 & 91,2 & 41,8 & 17,7 & $47,3 \pm 22,9$ \\
\hline EPT-1 & 67,2 & 46,5 & 55,1 & 44,3 & 67,4 & 104,3 & 52,7 & 22,3 & $56,1 \pm 25,3$ \\
\hline T: & & & & & & & &
\end{tabular}

T: temperatura $\left({ }^{\circ} \mathrm{C}\right)$. 
pouco acima do gradiente médio obtido a partir da relação ao mostrado na Fig. 3.

Os maiores gradientes estão situados nas porções NW e NE do estado (Fig. 4), enquanto os menores (abaixo de $24^{\circ} \mathrm{C} / \mathrm{km}$ ) ocupam toda a porção central da área de estudo, em uma faixa de sentido aproximado NS, que vai de São José do Rio Preto até a região de Marília. Não é possível associar esses valores mais baixos a ocorrência de mistura com águas mais frias, pois à exceção do poço de Vera Cruz (amostra VCZ-1), que não é o poço com o menor gradiente, todos os outros, situados nas cidades de Lins, Marília e São José do Rio Preto (respectivamente amostras LNS-2, MRL-1 e RPT-2), apresentam o basalto revestido.

As águas hipertermais do SAG são essencialmente bicarbonatadas sódicas, passando a bicarbonatadas-sulfatadas e cloretadas sódicas (Fig. 5), à exceção da amostra MAT-01, classificada como bicarbonatada cálcica.

A evolução hidroquímica das águas do SAG, e que imprime a classificação hidroquímica mencionada, foi descrita por inúmeros autores (Silva 1983, Meng \& Maynard 2001, Sracek \& Hirata 2002, Gastmans et al. 2010, Hirata et al. 2011, dentre outros) e envolve os processos geoquímicos de troca iônica, que explicariam a passagem das águas bicarbonatadas cálcicas para sódicas, seguida pelo aumento das concentrações de cloreto e sulfato, associado à mistura de águas enriquecidas nesses sais advindas de aquíferos sotopostos.

Esses processos são reconhecidos quando se avalia a relação existente entre as concentrações desses ânions e cátions com a condutividade elétrica, parâmetro que representa a dissolução mineral e o enriquecimento em sais ao longo das linhas de fluxo.
A alcalinidade das águas permanece praticamente constante com o aumento da condutividade elétrica (Fig. 10A), fato que corrobora a saturação em calcita alcançada pelas águas hipertermais do SAG (Tab. 4), enquanto as concentrações de cloreto e sulfato apresentam incremento semelhante, sem que seja reconhecida assembleia mineral capaz de fornecer o suprimento necessário desses ânions.

As concentrações de magnésio e potássio são geralmente muito baixas, não alcançando, em algumas amostras, os limites de detecção. Em relação aos cátions sódio e cálcio, observa-se comportamento inverso, com claro incremento, não linear, nas concentrações de sódio, tomando por referência a amostra com as menores concentrações, e diminuição nas concentrações de cálcio, que se mantêm aproximadamente constantes (Fig. 10B).

Gastmans et al. (2010) propõem que o aumento das concentrações de sódio na zona confinada do aquífero se dá por dois mecanismos. O primeiro está associado à troca iônica entre o cálcio e o potássio, enquanto o segundo está relacionado à mistura de águas ricas em cloreto e sódio advindas das unidades sotopostas ao SAG. O processo de mistura, segundo esses autores, ocorre quando as concentrações de sódio alcançam valores de $4 \mathrm{mmol} / \mathrm{L}$.

Os geotermômetros de quartzo (Q1 a Q4) utilizados nesse estudo estimam temperaturas acima das medidas em campo. Enquanto os geotermômetros Q1, Q2 e Q4 apresentam praticamente as mesmas temperaturas, de 30 a $40^{\circ} \mathrm{C}$ maiores que as medidas em campo, o Q3 mostra temperaturas cerca de $10^{\circ} \mathrm{C}$ menores que os geotermômetros citados acima, mas mantendo-se também acima daquelas medidas em campo. O geotermômetro de calcedônia (Q5) é aquele que aponta para as temperaturas mais próximas das
A

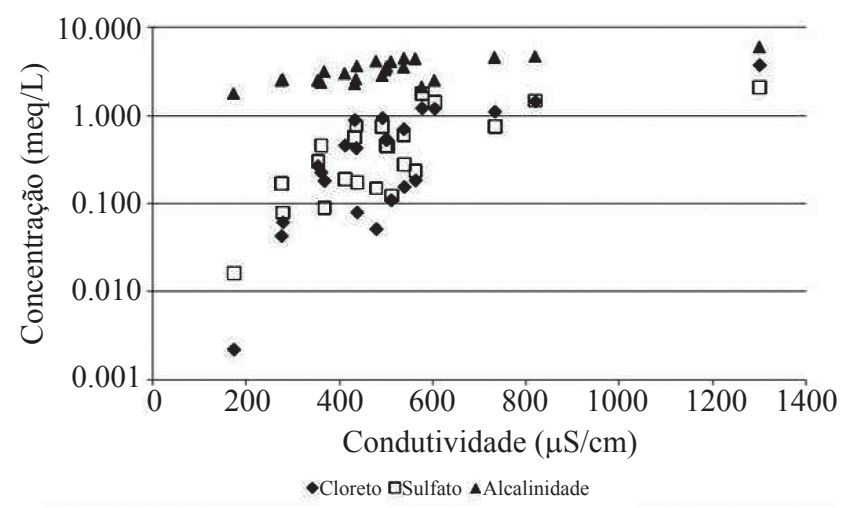

B

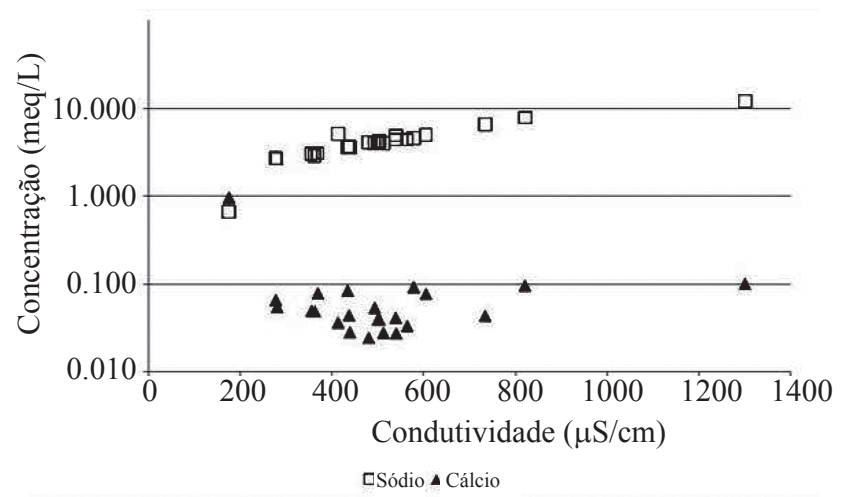

Figura 10 - Correlação entre as concentrações dos ânions (A) e cátions (B) principais e a condutividade elétrica das águas hipertermais do Sistema Aquifero Guarani na área de estudo. 
obtidas na saída dos poços (Fig. 7), podendo ser considerado, de maneira semelhante àquela observada por Pirlo (2004), como o que melhor se aplica a um sistema geotermal de baixa temperatura, situação na qual o SAG está inserido.

As exceções a essa correlação são as amostras VCZ-1, LNS-2, PMT-1, MRL-1 e TUP-1, cujas temperaturas são muito menores que as estimadas pelo geotermômetro Q5 e que correspondem àquelas situadas na região de menor gradiente termal da área. Apesar da hipótese da mistura com águas mais frias ser descartada, em função dos aspectos construtivos dos poços, o contato dessas águas com rochas efusivas e alto conteúdo em vidro vulcânico deve aumentar as concentrações de sílica dissolvidas na água e, consequentemente, gerar estimativas de temperaturas muito inferiores àquelas observadas (D'Amore et al. 1987).

As temperaturas calculadas pelos geotermômetros baseados na razão sódio e potássio apresentam, em geral, valores bem distintos daqueles observados nas saídas dos poços. Para os poços que apresentam temperaturas menores que $50^{\circ} \mathrm{C}$, as geotemperaturas são menores, enquanto para os valores acima desse limite não existe um padrão definido: ora as temperaturas são maiores, ora menores, e, por vezes, concordantes com as medidas de campo (Fig. 8, Tab. 5). É importante observar que as temperaturas calculadas com os geotermômetros SP1 e SP3 (Tab. 5), apontam valores extremos, principalmente negativos, e por esse motivo não foram representados na Fig. 8.

Para os poços com temperaturas inferiores a $50^{\circ} \mathrm{C}$, o geotermômetro SPC1 apresentou temperaturas muito próximas daquelas medidas em campo. Segundo Fournier (1977), esse geotermômetro pode ser apontado como o mais indicado para sistemas geotermais de baixa temperatura. Em contrapartida, o autor, no mesmo trabalho, afirma que outros geotermômetros baseados na razão $\mathrm{Na} / \mathrm{K}$ deveriam fornecer temperaturas superestimadas, o que não ocorre no caso do SAG.

As geotemperaturas obtidas a partir do equilíbrio termodinâmico entre as diversas fases minerais consideradas nesse estudo fornecem temperaturas abaixo das medidas nos poços, à exceção da calculada para o equilíbrio com a mica-K. Entretanto, a relação obtida é concordante, ou seja, nos poços com as maiores temperaturas as geotemperaturas também são maiores (Tab. 6).
As temperaturas obtidas a partir do equilíbrio do quartzo e da calcedônia são bem menores que as calculadas diretamente por meio das equações para cada um dos geotermômetros aplicados (Q1 a Q5), apresentando diferenças médias de $35^{\circ} \mathrm{C}$, mas que podem ultrapassar $80^{\circ} \mathrm{C}$ dependendo da equação considerada. Essas diferenças também foram observadas por D'Amore et al. (1987) e Pirlo (2004), sem que uma correlação com o equilíbrio termodinâmico fosse apontada.

No caso do SAG, a evolução hidroquímica proposta por Gastmans et al. (2010), que aponta para a existência de águas saturadas em calcedônia nas proximidades das áreas de afloramento e com temperaturas inferiores àquelas das águas avaliadas no presente estudo, pode explicar os resultados distintos observados. Como as águas atingem o equilíbrio com o quartzo e a calcedônia em temperaturas menores que as observadas nas águas hipertemais do SAG, a temperatura de equilíbrio será menor que a calculada a partir dos geotermômetros, que levam em consideração a relação direta entre a temperatura e as concentrações de sílica (Ferguson et al., 2009).

Apesar da condição de equilíbrio da caulinita na temperatura do reservatório, imposta para a simulação geoquímica no cálculo dos geotermômetros múltiplos, as temperaturas obtidas para o equilíbrio com os feldspatos (albita, anortita e feldspato potássico) são muito menores que as medidas em campo e não foram consideradas na avaliação. Esse resultado também foi obtido por Pirlo (2004), que o atribui esse comportamento ao fato de não existir equilíbrio termodinâmico entre os minerais e a água subterrânea.

Esse controle também estaria relacionado ao resultado obtido com os geotermômetros baseados no equilíbrio $\mathrm{Na} / \mathrm{K}$, uma vez que as formulações levam em consideração, segundo Karingithi (2009), a existência de equilíbrio entre os feldspatos e não com argilominerais, o que parece ser o caso das águas do SAG com maiores temperaturas.

As amostras com temperaturas abaixo de $50^{\circ} \mathrm{C}$, e que estão localizadas na zona de menor gradiente geotermal, foram aquelas em que as temperaturas calculadas pelo geotermômetro SPC1 mais se aproximaram das medidas em campo. Essas amostras são as únicas que se encontram em equilíbrio com os feldspatos (Fig. 6), uma condição necessária para a utilização desses geotermômetros (Fournier 1979).

Os geotermômetros avaliados não possibilitam a visualização clara da ocorrência de misturas entre 
águas. Entretanto algumas inferências podem ser feitas em relação aos geotermômetros de cátions, principalmente nas amostras que apresentam temperaturas mais elevadas. Aparentemente, a relação $\mathrm{Na} / \mathrm{K}$ para as amostras BRT-1, OLP-2, PDT-1 e EPT-1 tem condição de equilíbrio com águas mais quentes provenientes do aquífero sotoposto, enquanto as amostras BBD-1, RPT-2, PBT-1, ATB-2, JLS-1, AFM-1, BRG-1, GRP-1, PLT-1 e FDP-1 parecem estar em equilíbrio com o reservatório.

\section{CONCLUSÕES O SAG foi definido como} um sistema geotermal de baixa entalpia em função das temperaturas alcançadas por suas águas, e todas as avaliações anteriores a esse respeito (Teissedre \& Barner 1981, Silva 1983, Oleaga 2002, Hindi 2007, dentre outros) apenas as correlacionam com a profundidade do topo da unidade. A comparação entre as temperaturas medidas e as obtidas a partir de diversos geotermômetros permite avaliar a precisão e a aplicabilidade dos geotermômetros selecionados, bem como comparar os resultados em termos do equilíbrio termodinâmico e da evolução hidroquímica no reservatório.

Apesar da correlação existente entre a profundidade do topo do aquífero e a temperatura das águas subterrânea, a distribuição dos gradientes termais ao longo da área de estudo não se faz de maneira homogênea. Os maiores gradientes, que alcançam valores superiores a $30^{\circ} \mathrm{C} / \mathrm{km}$, estão situados nas porções NE e SW da área, enquanto na faixa central, que vai de São José do Rio Preto a Lins, estão localizados os poços com os menores gradientes, que alcançam valores inferiores a $25^{\circ} \mathrm{C} / \mathrm{km}$.

O geotermômetro de sílica baseado no equilíbrio com a calcedônia (Q5) foi o que apresentou os resultados mais próximos às temperaturas medidas em campo, à exceção dos poços localizados na faixa onde foram observados os menores gradientes geotermais, que, por sua vez, foram aqueles em que a temperatura obtida por meio do geotermômetro SPC1 apresentou os resultados mais próximos aos obtidos em campo, em razão dessas amostras estarem em equilíbrio termodinâmico com feldspatos.

$\mathrm{O}$ fato das águas do SAG estarem em equilíbrio com argilominerais, e não com feldspatos, explicaria as temperaturas obtidas a partir dos geotermômetros baseados no equilíbrio $\mathrm{Na} / \mathrm{K}$ e também o porquê dos geotermômetros múltiplos terem fornecido temperaturas discrepantes em relação àquelas medidas nas saídas dos poços.

Em relação à possibilidade de mistura de águas do SAG com as advindas das unidades subjacentes, evidências de ascensão de águas podem ser observadas na porção W-SW da área, onde os arenitos do SAG encontram-se em contato direto com as rochas da Formação Rio do Rasto, conforme mapeado por LEBAC (2008a).

\section{Referências}

Arnórsson S. 1970. Underground temperatures in hydrothermal areas in Iceland as deduced from the silica content of the thermal water. Geothermics, 2(1):536-541.

Arnórsson S. 1975. Application of the silica geothermometer in low temperature hydrothermal areas in Iceland. American Journal of Science, 275:763-784.

Arnórsson S. 1983. Chemical equilibria in Icelandic geothermal systems - implications for chemical geothermometry investigations. Geothermics, 12(23):119-128.

Araújo L.M., França A.B., Potter P.E. 1995. Aquífero gigante do Mercosul no Brasil, Argentina, Uruguai e Paraguai, mapas hidrogeológicos das formações Botucatu, Pirambóia, Rosário do Sul, Buena Vista, Misiones e Tacaurémbo. Curitiba, UFPR/Petrobras, 4 mapas, escala 1:5.000.000.

Araújo L.M., França A.B., Potter P.E. 1999. Hydrogeology of the Mercosul Aquifer System in the Paraná and Chaco-Paraná Basins, South America, and comparison with the Navajo-Nugget Aquifer System, USA. Hydrogeology Journal, 7(3):317-336.

Bonotto D.M. 2006. Hydro(radio)chemical relationships in the giant Guarani aquifer, Brazil. Journal of Hydrology, 323(1-4):353-386.

BRASIL. 1945. Decreto-Lei $n^{\circ} 7841$ de 08 de agosto de 1945. Disponível em: http://www.dnpm.gov.br/ conteudo.asp? IDSecao $=67 \&$ IDPagina $=84 \&$ IDLegisla $\mathrm{cao}=3$. Acessado em: 11/01/2011.

Caetano-Chang M.R. 1997. A Formação Pirambóia no Centro-Leste do estado de São Paulo. Tese de Livre Docência, Instituto de Geociências e Ciências Exatas, Universidade Estadual Paulista, Rio Claro, 196 p.

Caetano-Chang M.R. \& Wu F.T. 2006. Arenitos flúvioeólicos da porção superior da Formação Pirambóia, no Centro-Leste paulista. Revista Brasileira de Geociências, 36(2):296-304.

Campos H.C.N.S. 2000. Modelación conceptual y matemática del Aquífero Guarani, Cono Sur. Acta Geológica Leopoldinense, 23(4):3-50. 
Chang H.K. 2001. Proteção ambiental e gerenciamento sustentável integrado do Aqüífero Guarani - Tema 03. Relatório de Preparação do Projeto Sistema Aquífero Guarani. São Paulo, UNESP/IGCE, 54 p.

D’Amore F., Fancelli R., Caboi R. 1987. Observations on the application of chemical geothermometers to some hydrothermal systems in Sardinia. Geothermics, 16(3):271-282.

Dulanya Z., Morales-Simfors N., Sivertun Å. 2010. Comparative study of the silica and cation geothermometry of the Malawi hot springs: potential alternative energy source. Journal of African Earth Sciences, 57(4):321-327.

El-Fiky A.A. 2009. Hydrogeochemistry and geothermometry of thermal groundwater from the Gulf of Suez region, Egypt. JKAU: Earth Sciences, 20(2):71-96.

Ferguson G., Grasby S.E., Hindle S.R. 2009. What do aqueous geothermometers really tell us? Geofluids, 9(1):39-48.

Fournier R.O. 1977. Chemical geothermometers and mixing models for geothermal systems. Geothermics, 5(1-4):41-50.

Fournier R.O. 1979. A revised equation for the $\mathrm{Na} / \mathrm{K}$ geothermometer. Geothermal Resources Council Transaction, 3:221-224.

Fournier R.O. \& Rowe J.J. 1966. Estimation of underground temperatures from silica content of water from hot springs and wet-steam wells. American Journal of Sciences, 264(9):685-697.

Fournier R.O. \& Truesdell A.H. 1970. Chemical indicators of subsurface temperature applied to hot spring waters of Yellowstone National Park, Wyoming, USA. Geothermics, 2:529-535.

Fournier R.O. \& Truesdell A.H. 1973. An empirical Na-K$\mathrm{Ca}$ geothermometer for natural waters. Geochimica et Cosmochimica Acta, 37(5):1255-1275.

Fournier R.O., White D.E., Truesdell A.H. 1974. Geochemical indicators of subsurface temperature - part 1, basic assumptions. Journal Research U.S. Geological Survey, 2(3):259-262.

França A.B., Araújo L.M., Maynard J.B. Potter P.E. 2003. Secondary porosity formed by deep meteoric leaching: Botucatu eolanite, Southern South America. American Association of Petroleum Geologistx Bulletin, 87(7):1073-1082.

Gastmans D. 2007. Hidrogeologia e hidroquímica do Sistema Aqüifero Guarani na Porção Ocidental da Bacia Sedimentar do Paraná. Tese de Doutorado, Instituto de Geociências e Ciências Exatas, Universidade Estadual Paulista, Rio Claro, 194 p.

Gastmans D., Chang H.K., Hutcheon I. 2010. Groundwater geochemical evolution in the northern portion of the Guarani Aquifer System (Brazil) and its relationship to diagenetic features. Applied Geochemistry, 25(1):16-33.
Gesicki A.L.D. 2007. Evolução diagenética das formações Pirambóia e Botucatu (Sistema Aqüífero Guarani) no estado de São Paulo. Tese de Doutorado Instituto de Geociências Universidade de São Paulo São Paulo 175 p.

Giggenbach W.F. 1988. Geothermal solute equilibria. Derivation of Na-K-Mg-Ca geoindicators. Geochimica et Cosmochimica Acta, 52(12):2749-2765.

Gomes A.J.L. \& Hanza V.M. 2004. Mapeamento de gradientes geotérmicos no estado de São Paulo. In: SBGf, I Simp. Reg. Soc. Bras. Geofísica, Atas, 4 p.

Hamza V.M., Eston S.M., Araújo R.L.C. 1978. Geothermal energy prospects in Brazil: a preliminary analysis. Pure and Applied Geophysics, 117:180-195.

Hindi E.C. 2007. Hidroquímica e hidrotermalismo do Sistema Aqüífero Guarani no estado do Paraná. Tese de Doutorado, Setor de Ciências da Terra, Universidade Federal do Paraná, Curitiba, 154 p.

Hirata R., Gesicki A., Sracek O., Bertolo R., Giannini P.C., Aravena R. 2011. Relation between sedimentary framework and hydrogeology in the Guarani Aquifer System in São Paulo state, Brazil. Journal of South American Earth Sciences, 31(4):444-456.

Karingithi C.W. 2009. Chemical geothermometers for geothermal exploration. In: Short Course IV on Exploration for Geothermal Resources, UNU-GTP, 12 p.

Laboratório de Estudos de Bacias (LEBAC). 2008a. Mapa hidrogeológico do Sistema Aquifero Guarani. Rio Claro, 8 mapas, escala 1:3.000.000.

Laboratório de Estudos de Bacias (LEBAC). 2008b. Informe final de hidrogeologia regional do $S A G$. Rio Claro, 8 mapas.

Mazor E., Levitte D., Truesdell A.H., Healy J., Nissenbaum, A. 1980. Mixing models and ionic geothermometers applied to warm (up to $60 \mathrm{deg}$ ) springs, Jordan Rift Valley, Israel. Journal of Hydrology, 45(1/2):1-19.

Meister E.M. 1973. Gradientes geotérmicos nas bacias sedimentares brasileiras. Boletim Técnico da Petrobras, 16:221-232.

Meng S.X. \& Maynard J.B. 2001. Use of statistical analysis to formulate conceptual models of geochemical behavior: water chemical data from the Botucatu Aquifer in Sao Paulo state, Brazil. Journal of Hydrology, 250(1-4):78-97.

Navarro A., Font X., Viladevall M. 2011. Geochemistry and groundwater contamination in the La Selva geothermal system (Girona, Northeast Spain). Geothermics, 40(4):275-285.

Oleaga A.B. 2002. Contribucíon a la hidrogeologia del acuífero Guarani en el sector Uruguay. Un enfoque integral. Dissertação de Mestrado, Universidade Nacional Autônoma de México, Cidade do México, 119 p.

Pang Z. \& Reed M. 1998. Theoretical chemical thermometry on geothermal waters: problems and methods. Geochimica et Cosmochimica Acta, 62(6):1083-1091. 
Parkhurst D.L. \& Appelo C.A.J. 1995. User's guide to PHREEQC (Version 2) - A computer program for speciation. speciation, batch-reaction, onedimensional transport, and inverse geochemical calculations. Denver, U.S. Geological Survey, WaterResources Investigations Report 99-4259, 312 p.

Pirlo M.C. 2004. Hydrogeochemistry and geothermometry of thermal groundwaters from the Birdsville Track Ridge, Great Artesian Basin, South Australia. Geothermics, 33(6):743-774.

Prol-Ledesma R.M. 1991. Chemical geothermometers applied to the study of thermalized aquifers in Guaymas, Sonora, Mexico: a case history. Journal of Volcanology and Geothermal Research, 46(1-2):49-59.

PyT Consultora srl. 2007. Informe final de releviamentos geológicos. Buenos Aires, Projeto Aquífero Guarani, Relatório Técnico, 93 p.

Rebouças A.C. 1976. Recursos hídricos subterrâneos da Bacia do Paraná: análise de pré-viabilidade. Tese de Livre Docência, Instituto de Geociências, Universidade de São Paulo, São Paulo, 143 p.

Reed M.H. 1982. Calculation of multicomponent chemical equilibria and reaction processes in systems involving minerals, gases and an aqueous phase. Geochimica et Cosmochimica Acta, 46(4):513-528.

Reed M. \& Spycher N. 1984. Calculation of pH and mineral equilibria in hydrothermal waters with application to geothermometry and studies of boiling and dilution. Geochimica et Cosmochimica Acta, 48(7):1479-1492.

Rimstidt J.D. 1997. Quartz solubility at low temperatures. Geochimica et Cosmochimica Acta, 61(13):2553-2558.

Santos J.S. 2001. Proteção Ambiental e Gerenciamento Sustentável Integrado do Aquífero Guarani - Tema 03 Estudio Del uso Actual y Potencial Del Acuífero Guarani. Montevideo, Universidad de la Republica. Relatório de Preparação do Projeto Sistema Aquífero Guarani. 54 p.

SÃO PAULO. DAEE/IG/IPT/CPRM. 2005. Mapa de águas subterrâneas do estado de São Paulo. São Paulo, CPRM, 1 mapa, escala 1:1.000.000.

Silva R.B.G. da. 1983. Estudo hidroquímico e isotópico do Aquífero Botucatu no Estado de São Paulo. Tese de Doutorado, Instituto de Geociências, Universidade de São Paulo, São Paulo, 133 p.
Soares P.C. 1973. O Mesozóico Gondwânico no estado de São Paulo. Tese de Doutorado, Departamento de Geologia e Mineralogia, Faculdade de Ciências e Letras de Rio Claro, Rio Claro, 153 p.

Soares P.C. 1975. Divisão estratigráfica do Mesozóico no estado de São Paulo. Revista Brasileira de Geologia, 5(4):229-251.

Sracek O. \& Hirata R. 2002. Geochemical and stable isotopic evolution of the Guarani Aquifer System in the state of São Paulo, Brazil. Hydrogeology Journal, 10:643-655.

Teissedre J.M. \& Barner U. 1981. Comportamento geotérmico e geoquímico das águas do Aquífero Botucatu na Bacia do Paraná. Revista Águas Subterrâneas, 4:85-95.

Tole M.P., Ármannsson H., Zhong-He P., Arnórsson S. 1993. Fluid/mineral equilibrium calculations for geothermal fluids and chemical geothermometry. Geothermics, 22(1):17-37.

Truesdell A.H. 1976. Sumary of section III, Geochemical techniques in exploration. In: Proceedings of the Second United Nations Symposium on the development and use of geothermal resources. San Francisco, p. liii-lxiii.

Uyeda S. \& Watanabe T. 1970. Preliminary report of terrestrial heat flow study in the South American continent, distribution of geothermal gradients. Tectonophysics, 10(1-3):235-242.

Verma S.P. \& Satoyo E. 1997. New improved equations for $\mathrm{Na} / \mathrm{K}, \mathrm{Na} / \mathrm{Li}$ and $\mathrm{SiO}_{2}$ geothermometers by outlier detection and rejection. Journal of Volcanology and Geothermal Resources, 79(1):9-23.

Vitorello I., Hamza V.M., Pollack H.N., Araujo R.L.C. 1978. Geothermal investigations in Brazil. Revista Brasileira de Geociências, 8:71-89.

Washburne C.W. 1930. Petroleum Geology of the State of São Paulo, Brazil. São Paulo, Comissão Geográfica e Geológica do Estado de São Paulo, Boletim. 282p.

Manuscrito ID 26019

Recebido em: 01/03/2012 Aprovado em: 25/09/2012 